\title{
Análisis de la tipificación de la corrupción privada en el Perú: ¿Una estrategia global contra la corrupción también debe involucrar a los particulares? ¿Y a las empresas? $\left.{ }^{*}\right)$
}

\section{An Analysis of the Criminal Typification of Private Corruption in Peru: Should a global strategy against corruption involve the private sector? And what about companies?}

\author{
Cecilia Madrid Valerio ${ }^{(*)}$ \\ Pontificia Universidad Católica del Perú \\ Walter Palomino Ramírez ${ }^{(* *)}$ \\ Pontificia Universidad Católica del Perú
}

\begin{abstract}
Resumen: El presente trabajo busca determinar, a través del análisis de los antecedentes de los delitos de corrupción en el ámbito privado (artículo 241-A) y corrupción al interior de entes privados (artículo 241-B), la necesidad político-criminal de su tipificación y la importancia de su represión en una estrategia global contra de la corrupción, que involucre responsabilizar a los particulares y a las personas jurídicas que se beneficien de los actos corruptos cometidos por estos, conforme a las reglas establecidas en la Ley 30424.
\end{abstract}

Palabras clave: Derecho Penal - Delitos - Corrupción - Ámbito privado - Tipificación - Perú

Abstract: In this article the authors analyze the background of the crimes of corruption
in the private sphere (section 241-A) and corruption inside private entities (section 241-
B). The purpose is to determine the political-criminal need for their legal recognition and
the importance of their repression as part of a global strategy against corruption that
aims to hold accountable both individuals and private entities that benefit from acts of
corruption commited by them, according to the rules established by Peruvian Law 30424 .

Keywords: Criminal Law - Criminal offense - Corruption - Private sector - Legality - Peru

$\left(^{*}\right) \quad$ Nota del Editor: este artículo fue recibido el 5 de marzo y su publicación fue aprobada el 27 de abril de 2019.

${ }^{* *}$ Profesora de Cumplimiento Normativo en el Centro de Educación Continua de la Pontificia Universidad Católica del Perú. Abogada por la Pontificia Universidad Católica del Perú. Especialista en Cumplimiento Normativo en Materia Penal por la Universidad Castilla de la Mancha (España) y por la Asociación Española de Normalización (AENOR). Especialista en Compliance y Buenas Prácticas Corporativas (Universidad del Pacífico). Con Certificación Anti Lavado de Dinero, Nivel Asociado (AMLCA), emitido por la Florida International Bankers Association/Florida International University. Correo electrónico: ceciliamad@gmail.com.

$\left.{ }^{(* *}\right)$ Profesor de Cumplimiento Normativo en el Centro de Educación Continua de la Pontificia Universidad Católica del Perú. Abogado y Magíster por la Pontificia Universidad Católica del Perú. Especialista en Cumplimiento Normativo en Materia Penal por la Universidad Castilla de la Mancha (España) y por la Asociación Española de Normalización (AENOR). Especialista en Compliance y Buenas Prácticas Corporativas (Universidad del Pacífico). Con Certificación Anti Lavado de Dinero, Nivel Asociado (AMLCA), emitido por la Florida International Bankers Association/Florida International University. Correo electrónico: wpalomino@pucp.pe 
Análisis de la tipificación de la corrupción privada en el Perú: ¿Una estrategia global contra la corrupción también debe involucrar a los particulares? ¿Y a las empresas?

An Analysis of the Criminal Typification of Private Corruption in Peru: Should a global strategy against corruption involve the private sector? And what about companies?

\section{Introducción}

En el marco de la IV Conferencia Anticorrupción. Instrumentos Internacionales en la lucha Anticorrupción, que se realizó el 17 de mayo de 2017, el magistrado supremo Víctor Prado Saldarriaga, al dar cuenta de las diversas modificaciones legales en materia de prevención y control de la corrupción, sostuvo que la criminalización de la corrupción privada sigue siendo uno de los temas tabú(1).

El citado catedrático de la Pontificia Universidad Católica del Perú evidenció así cómo ha reaccionado por bastante tiempo el legislador peruano al momento de evaluar la necesidad de construir tipos penales que prohíban los actos de corrupción entre particulares, los cuales, de acuerdo a un sector de la doctrina, se tratan de actos que no afectan únicamente a las empresas, ni son solo de interés para sus socios o fundadores, sino que representan un serio riesgo para importantes intereses públicos (Montoya 2012) ${ }^{(2)}$.

Pese a ello, lo cierto es que nuestro Código Penal siempre se orientó a la sanción de los comportamientos de corrupción pública, de manera que las posibilidades de una contención penal de la corrupción estuvo limitada a las conductas consideradas como un peligro intolerable para el correcto y regular funcionamiento de la administración pública ${ }^{(3)}$, en un escenario típico donde debían ser dos las partes que interviniesen: el funcionario que acepta o solicita el "pago" por la venta de la función pública y el sujeto que compra el "servicio" o recibe el ofrecimiento del funcionario (Montoya 2015, 95).

Por ello, los sobornos ofrecidos o aceptados en el plano privado, sin la intervención de funcionarios públicos, estuvieron al margen del Derecho Penal. Esto es que todos aquellos casos donde tanto el corrompido como el corruptor pertenecían al sector privado (Hurtado Pozo, 5) no se consideraron como comportamientos que mereciesen ser tipificados y castigados a través del Código Penal.

Sin embargo, desde el 4 de setiembre del 2018 esa visión sobre la corrupción privada cambió, ya que, a través del Decreto Legislativo 1385, se busca ahora sancionar penalmente los actos de corrupción realizados entre particulares ${ }^{(4)}$. En específico, se criminalizaron los actos de corrupción entre privados que se cometan en las relaciones comerciales (artículo 241-A) y la realización de actos desleales que provoquen un perjuicio a una persona jurídica (artículo 241-B).

Aquello da cuenta de un enfoque amplio sobre corrupción que permite el castigo del ofrecimiento o entrega de sobornos en contextos exclusivamente privados, donde mínimamente deberán intervenir dos individuos: el funcionario de la persona jurídica que acepta, reciba o solicita el soborno y aquel otro sujeto que prometa, ofrezca o conceda el indebido beneficio.

Nos encontraríamos, según se indica en dicha norma, ante dos nuevas figuras penales que tendrían por objeto sancionar penalmente los actos de corrupción cometidos entre privados que afectan el normal desarrollo de las relaciones comerciales y la competencia leal entre empresas (artículo 1 del Decreto Legislativo 1385), lo que, evidentemente, se diferencia de aquellos delitos que recriminan el uso abusivo del poder público como medio para obtener ventajas o beneficios indebidos (Bregaglio 2015, 115) (Título XVIII del Libro II del Código Penal).

Dicho ello, a continuación analizaremos los antecedentes de los delitos de corrupción en el ámbito privado (artículo 241-A) y corrupción al interior de entes privados (artículo 241-B), con el propósito de determinar la necesidad políticocriminal de su tipificación, el bien jurídico que se tutela en cada caso y las características típicas de esos delitos. A partir de lo cual buscaremos determinar la importancia de su represión, en una estrategia global en contra de la corrupción, que involucre responsabilizar a los individuos particulares y a las personas jurídicas que se beneficien de los actos corruptos cometidos por los primeros, conforme a las reglas establecidas en la Ley $30424^{(5)}$.

(1) Víctor Prado Saldarriaga. 2017. "Recientes desarrollos de las políticas internacionales contra la corrupción en el Perú" Conferencia presentada en "IV Conferencia Anticorrupción. Instrumentos Internacionales en la lucha Anticorrupción”, 17 de mayo de 2017.

(2) Véase también: Juan María Terradillos Basoco, "Corrupción, globalización y derecho penal económico. Lección de apertura del año académico de la Facultad de Derecho de la Pontificia Universidad Católica del Perú", Derecho PUCP 74, $2015,12$.

(3) Yván Montoya Vivanco coord., Manual sobre delitos contra la administración pública (Lima: Idehpucp - Open Society Foundations), 35. Sigue una posición similar: Víctor Prado Saldarriaga, Delitos y penas. Una aproximación a la Parte Especial (Lima: Ideas Solución Editorial SAC, 2015), 192.

(4) El Poder Ejecutivo emitió el Decreto Legislativo 1385, en el marco de la "Ley que delega en el Poder Ejecutivo la Facultad de legislar en materia de gestión económica y competitividad, de integridad y lucha contra la corrupción, de prevención y protección de personas en situación de violencia y vulnerabilidad y de modernización de la gestión del Estado" (Ley 30823).

(5) Nos referimos a la Ley 30424, que se aprobó mediante el Decreto Supremo 002-2019-JUS, y entró en vigor el 1 de enero de 2018. 


\section{2. ¿Qué se debe entender por corrupción?}

La corrupción es un fenómeno complejo que requiere ser evaluado desde distintos enfoques, a fin de comprenderlo y combatirlo(6). Su naturaleza, según explica Yván Montoya, es tan compleja que es objeto de estudio por diversas disciplinas científicas $^{(7)}$, de manera que un enfoque limitado al ámbito penal de ninguno modo podrá abarcar toda la amplitud y complejidad de dicho fenómeno social.

Quizá aquello explique que ni la Convención de Naciones Unidas contra la Corrupción ${ }^{(8)}$, ni la Convención Interamericana contra la Corrupción hayan preferido brindar una definición cerrada de aquel fenómeno, sino enumerar algunas conductas que deban entenderse como actos de corrupción y, por tanto, ser sancionadas (Montoya 2015, 20). Sin embargo, la falta de una definición terminante sobre qué se entiende por corrupción de ningún modo debe conducirnos a pensar que se trata de un problema menor, sino todo lo contrario, pues tales dificultades son, en realidad, un reflejo de la amplitud de su contenido y de que aquel termino es empleado para denotar distintas situaciones de gran importancia para la sociedad.

Así, para Meini, el término corrupción se utiliza para denotar distintas situaciones: "Por un lado, se emplea para significar el fenómeno social de la corrupción, por otro, para hacer referencia al delito de corrupción como una de las modalidades de delitos contra la Administración Pública" $(2007,59)$. Siendo eso así, no le falta razón a Hurtado cuando sostiene que los comportamientos reprimidos en el Código Penal solo vendrían a ser una parte de aquel fenómeno social amplio y complejo (Hurtado Pozo, 1).

Incluso, como apuntan Ugaz Sánchez Moreno y Ugaz Heudebert, aún cuando desde hace más de veinte años Transparencia Internacional popularizó la definición de corrupción como el "abuso de una posición pública para obtener un beneficio privado", lo cierto es que aquella definición se trata solo de una fórmula sintética de describir la esencia de la corrupción, pero que no agota su contenido (2017, 27-28).

Por todo ello, es importante conocer cómo se ha definido la corrupción en nuestro país: Por ejemplo, en el Plan Nacional de Lucha contra la Corrupción 2012 - 2016(9), se planteó la siguiente definición operativa: "Uso indebido del poder para la obtención de un beneficio irregular, de carácter económico o no económico, a través de la violación de un deber de cumplimiento, en desmedro de la legitimidad de la autoridad y de los derechos fundamentales de la persona"(10).

Luego, en la Política Nacional de Integridad y Lucha contra la Corrupción ${ }^{(11)}$, que es el más importante instrumento de gestión en esta materia(12), se define la corrupción como "el mal uso del poder público o privado para obtener un beneficio indebido; económico,

(6) Yván Montoya Vivanco, coord., Manual sobre delitos contra la administración pública (Lima: Idehpucp - Open Society Foundations, 2015), 35. Sigue una posición similar: Víctor Prado Saldarriaga, Delitos y penas. Una aproximación a la Parte Especial (Lima: Ideas Solución Editorial SAC, 2017), 17.

(7) Montoya indica, a modo de resumen, que son tres los enfoques más importantes sobre corrupción: (i) el enfoque económico, (ii) el enfoque jurídico-institucional y (iii) el enfoque cultural. Al respeto ver: Yván Montoya Vivanco, coord., Manual sobre delitos contra la administración pública (Lima: Idehpucp - Open Society Foundations, 2015), 35. Sigue una posición similar: Víctor Padro Saldarriaga. Delitos y penas. Una aproximación a la Parte Especial (Lima: Ideas Solución Editorial SAC, 2017), 18 y 19.

(8) En el Preámbulo de la Convención de las Naciones Unidas contra la Corrupción se da cuenta de tal carácter complejo, al sostenerse la necesidad de "(...) un enfoque amplio y multidisciplinario para prevenir y combatir eficazmente la corrupción (...)", la cual "(...) ha dejado de ser un problema local para convertirse en un fenómeno transnacional que afecta a todas las sociedades y economías (...). Ver: https://www.unodc.org/pdf/corruption/publications_unodc_convention-s.pdf

(9) Aprobado mediante Decreto Supremo 044-2018-PCM del 26 de abril de 2017. Disponible en internet: http://can.pcm.gob.pe/wpcontent/uploads/2018/04/Decreto-Supremo-N\%C2\%B0-048-2018-que-aprueba-el-Plan-Nacional-de-Integridad-y-Lucha-contra-laCorrupci\%C3\%B3n-2018-2021.pdf

(10) Véase: http://can.pcm.gob.pe/wp-content/uploads/2013/02/Plan-Nacional-Anticorrupcion-2012-2016-DS-119-2012-PCM.pdf. Para Novoa se trata de un concepto acertado, pues comprende no solo los actos de corrupción pública, sino también "aquellas conductas cometidas por agentes del sector privado y que también pueden tener efectos perjudiciales para la ciudadanía". Véase al respecto: Yvana Novoa Curich. La corrupción como mecanismo de discriminación. Derecho y Sociedad 47, 2016, 216. Posiblemente, la base de dicha afirmación es que el uso indebido del poder, al que se hace referencia en el citado instrumento, no se acota en clave de poder público o poder público encargado por elección, selección, nombramiento o designación, que caracteriza específicamente a la corrupción pública. Véase: Yván Montoya Vivanco., Manual sobre delitos contra la administración pública (Lima: Idehpucp - Open Society Foundations, 2015), 18.

(11) Promulgada por el Poder Ejecutivo el 14 de setiembre del 2017 mediante el Decreto Supremo 092-2017-PCM.

(12) Véase: http://can.pcm.gob.pe/normas-nacionales/politica-nacional-de-integridad-y-lucha-contra-la-corrupcion/ 
Análisis de la tipificación de la corrupción privada en el Perú: ¿Una estrategia global contra la corrupción también debe involucrar a los particulares? ¿Y a las empresas?

An Analysis of the Criminal Typification of Private Corruption in Peru: Should a global strategy against corruption involve the private sector? And what about companies?

no económico o ventaja; directa o indirecta; por agentes públicos, privados o ciudadanos (...)"(13). Se precisa, además, que la noción del mal uso del poder comprende tanto al poder público como al privado, por lo que los mecanismos para la prevención y combate de la corrupción deben alcanzar a la corrupción privada(14).

En el Plan Nacional de Lucha contra la Corrupción 2018 - $2021^{(15)}$ no se ofrece una definición operativa sobre qué debe entenderse por corrupción; sin embargo, se indicó que se organizaron las diversas perspectivas y se formó un marco analítico que articuló las anteriores aproximaciones, considerando las limitaciones operativas y la diversidad conceptual de los instrumentos precedentes, con lo cual, en nuestro opinión, se habrían rescatado los criterios que condujeron a la definición operativa planteada en el Plan Nacional de Lucha contra la Corrupción 2012 - 2016.

Esto se aprecia en el hecho de que, en el mencionado instrumento, no solo se indicó que la corrupción es un fenómeno "(...) complejo, multicausal y multidimensional $(\ldots)^{(16) "}$ que no puede ser abordado desde un solo enfoque ni por una sola entidad, sino que también se manifestó que uno de los ámbitos del citado Plan Nacional "involucra sin distinción a todas las entidades públicas, privadas, empresas, ciudadanía y colectivos sociales, los cuales deben implementar modelos de prevención (...)", reconociéndose así que el combate de dicho fenómeno trasciende del ámbito público para involucrar también al privado.
En efecto, de acuerdo al Plan Nacional de Lucha contra la Corrupción 2018 - 2021, es necesario que "las empresas desarrollen buenas prácticas corporativas alineadas al modelo de prevención contenido en la Ley 30424"; es decir, que se hallen en sintonía con el modelo de cumplimiento normativo en materia penal que se encuentra previsto en el artículo 17 de la Ley que regula la responsabilidad administrativa (penal) de las personas jurídicas ${ }^{(17)}$, la cual —según indica Reaño- se gestó con el propósito de que se apruebe la candidatura peruana a la Organización para la Cooperación y el Desarrollo Económico(18).

La principal virtud de los programas de cumplimiento normativo es que pueden eximir de responsabilidad a las personas jurídicas que lo hayan implementado oportunamente. Incluso, si el programa de prevención se adopta luego de la comisión de cualquiera de los delitos que prevé dicha norma (ejemplo: cohecho activo transnacional, cohecho activo genérico, cohecho activo específico, etc.), la persona jurídica podría conseguir que se atenúen las sanciones que se le podrían

(13) Véase: http://can.pcm.gob.pe/wp-content/uploads/2017/09/D.S.-N\%C2\%B0-092-2017-Pol\%C3\%ADtica-Nacional-de-Integridad-yLucha-contra-la-Corrupci\%C3\%B3n.pdf.

(14) Cabe aclara que, al momento de indicarse que la corrupción es un problema público, en aquel documento solo se hace referencia a la utilización del poder público; sin embargo, luego se indica que: "Diversos autores, hoy en día, hacen la precisión de que los comportamientos corruptos están directamente asociados al mal uso de posiciones privilegiadas que no solo se configuran en la esfera pública, sino que inclusive tienen implicaciones en la esfera privada. Por ejemplo Munive (2016) señala que el mal uso de una posición privilegiada o el uso indebido del poder se materializa mediante comportamientos que exceden las facultades y limitaciones que un cargo público o privado detenta, reemplazando la finalidad que da significancia a dicha posición para ser reemplazada por fines ajenos y que lindan con la transgresión de disposiciones normativas, principios administrativos y reglas formales" Ver: http:// can.pcm.gob.pe/wp-content/uploads/2018/03/Politica-Nacional-de-Integridad-y-Lucha-contra-la-Corrupci\%C3\%B3n.pdf

(15) Aprobado mediante Decreto Supremo 044-2018-PCM del 26 de abril de 2018. Disponible en internet: http://can.pcm.gob.pe/wpcontent/uploads/2018/04/Decreto-Supremo-N\%C2\%B0-048-2018-que-aprueba-el-Plan-Nacional-de-Integridad-y-Lucha-contra-laCorrupci\%C3\%B3n-2018-2021.pdf.

(16) Capítulo IV del Decreto Supremo 044-2018-PCM.

(17) La Ley 30424 se emitió el 01 de abril de 2016 y entró en vigor el 1 de enero de 2018. Sobre el carácter penal de la responsabilidad autónoma de las personas jurídicas previsto en la Ley 30424 puede consultarse: Walter Palomino Ramirez y Cecilia Madrid Valerio, Responsabilidad administrativa de las personas jurídicas e importancia de los programas de cumplimiento, a apropósito del Decreto Legislativo 1352, Actualidad Penal 38 (marzo 2017).

(18) José Reaño Pescheira, "La utilidad de los programas de criminal compliance para las empresas que operan en Perú", Revista PUCP 68 (2015), 148. A mayor abundamiento, cabe indicar que la integración del Perú como Estado miembro de la Organización para la Cooperación y el Desarrollo Económico exigió también la previa suscripción de la Convención Contra el Soborno Transnacional, que no podría ser suscrita en tanto no se encuentre regulado un régimen autónomo de responsabilidad para las personas jurídicas que incurran en actos de corrupción. En la actualidad, el Perú ha ratificado la Convención Contra el Soborno Transnacional, así como también lo hicieron Argentina, Brasil, Chile, Colombia, Costa Rica, México, entre otros. Al ratificar la Convención Antisoborno, el secretario general de la OCDE destacó que para su inclusión, el Perú tuvo que realizar cambios significativos a fin de fortalecer su combate contra la corrupción transnacional y alinearse con los estándares de la convención: "La entrada en vigor a principios de este año de la ley de responsabilidad corporativa de Perú, que también abarca el soborno doméstico (...) es una clara demostración del compromiso político del Perú para enfrentar la corrupción en todas sus formas". Ver al respecto: https://www.mef.gob.pe/es/ noticias/notas-de-prensa-y-comunicados?id=5685 
imponer, en vista de que estaría mostrando su interés por evitar que un hecho de tal naturaleza ocurra nuevamente ${ }^{(19)}$.

Precisamente, en el Reglamento de la Ley 30424(20) se indicó que los modelos de prevención en materia penal buscan "promover la integridad y transparencia en la gestión de las personas jurídicas"(21). Siendo esto así, a través de la asignación de efectos eximentes o atenuantes a dichos programas de cumplimiento normativo en materia penal, el Estado estaría "premiando" la implementación e institucionalización de una cultura de cumplimiento de la legalidad en las personas jurídicas ${ }^{(22)}$.

Por ello mismo, la no implementación de dichos programas de prevención de riesgos penales podría conducir a que se responsabilice a las personas jurídicas, conforme se formula en la Convención de Naciones Unidas contra la Corrupción y en el Convenio de lucha contra la corrupción de la Organización para la Cooperación y el Desarrollo Económico, si es que finalmente se llevan a cabo prácticas corruptas ${ }^{(23)}$.

En ese contexto, no es de extrañar que, en la Guía Práctica del Programa anticorrupción de ética y cumplimiento para las empresas de la Oficina de las Naciones Unidas Contra la Droga y el Delito, se sostenga lo siguiente:

"Ni los gobiernos ni las empresas pueden combatir la corrupción por sí solos. El sector público y el sector privado deben trabajar de consuno en esa labor. A tal efecto, el instrumento internacional anticorrupción más importante, la Convención de las Naciones Unidas contra la Corrupción (CNUCC), considera esencial la participación del sector privado en la lucha contra la corrupción.

En la actualidad, se acepta ampliamente que las empresas tienen la responsabilidad de actuar como buenos ciudadanos corporativos" $(2013,1)$.

Así las cosas, queda claro que la corrupción es un fenómeno social, complejo, multicausal y multidimensional, donde los delitos que castigan la corrupción pública solo suponen la contención penal de ciertos comportamientos de riesgo para el correcto y regular funcionamiento de la administración pública (Montoya 2015, 35) ${ }^{(24)}$, lo que no comprende todos los ángulos necesarios para combatir penalmente aquello que desde hace varios años se concibe como un fenómeno que debe ser enfrentado tanto en el ámbito público como en las relaciones entre particulares (Bolea 2013, 3).

Es necesario, entonces, que se asuma, en el ámbito penal, una concepción amplia acerca de lo que debe entenderse por corrupción, a fin de que se ponga de manifiesto que comprende "toda violación por parte de un individuo - dotado de poderes de decisión (ya sea en el ámbito público o en otros, como por ejemplo, el ámbito privado de las relaciones comerciales) - de las reglas que rigen su actividad, con el objetivo de procurar para sí mismo o para un tercero una ventaja de cualquier índole" (Encinar 2017, 65).

Esto deberá conducir a que la intervención del Derecho Penal no se limite al castigo de la corrupción pública, sino que también abarque la corrupción privada. La intervención del Derecho penal se justifica a razón de que las conductas de soborno en la contratación privada también "(...) constituyen una forma de corrupción que debe ser atajada, si se quiere contar con un régimen de competencia libre y leal" (Encinar 2017, 52).

En otras palabras, para combatir la corrupción de acuerdo a una estrategia que sintonice con la Política Nacional de Integridad y Lucha contra la Corrupción, así como con el Plan Nacional de Lucha contra la Corrupción 2018-2021, y que se encuentre en línea con importantes instrumentos

(19) Según los arts. 2 y 3 de la Ley 30424, las entidades de derecho privado, así como las asociaciones, fundaciones, organizaciones no gubernamentales y comités no inscritos, las sociedades irregulares, los entes que administran un patrimonio autónomo y las empresas del Estado peruano o sociedades de economía mixta pueden ser sancionadas por la comisión de los delitos de cohecho activo transnacional, cohecho activo genérico, cohecho activo específico, colusión ilegal, tráfico de influencias, lavado de activos y financiamiento del terrorismo, siempre que cualquiera de aquellos ilícitos penales se realice en su nombre o por cuenta de ellas y en su beneficio.

(20) El 09 de enero de 2019 se publicó el Reglamento de la Ley 30424

(21) Artículo 1 del Reglamento de la Ley 30424.

(22) Al respecto, en la experiencia española, puede consultarse: Carlos Gómez-Jara Díez. "Capítulo1. El sistema de responsabilidad penal de las personas jurídicas en el nuevo Código Penal español”, en El nuevo Código Penal, coord., Nuria Pastor Muñoz y Jesús María Silva Sanchez (dir.), (Madrid: La Ley, 2012), 50.

(23) Ver al respecto: Programa anticorrupción de ética y cumplimiento para las empresas: Guía Práctica. 2013 (Naciones Unidas: Oficina de Naciones Unidas contra la Droga y el Delito en Viena, 2013), 6.

(24) Sigue una posición similar: Víctor Prado Saldarriaga, Delitos y penas. Una aproximación a la Parte Especial (Lima: Ideas Solución Editorial SAC, 2017), 192. 
Análisis de la tipificación de la corrupción privada en el Perú: ¿Una estrategia global contra la corrupción también debe involucrar a los particulares? ¿Y a las empresas?

An Analysis of the Criminal Typification of Private Corruption in Peru: Should a global strategy against corruption involve the private sector? And what about companies?

internacionales, es necesario que se procure una estrategia integral de persecución y sanción de todas las formas de corrupción, que comprenda cuán útil es la implementación de políticas públicas y la promoción de valores en el ámbito público y privado, pero que también acepte como necesaria la intervención del Derecho Penal cuando todos los intervinientes son individuos particulares que realizan comportamientos altamente ofensivos para importantes intereses públicos.

\section{Antecedentes del Decreto Legislativo No 1385}

\subsection{Contexto internacional}

San Martín indica que la política de Estado en materia de combate a la corrupción no es de libre configuración, pues esta viene delimitada por un consenso internacional o, incluso, definida por el derecho internacional (2012, 42). El citado jurista sostiene que existen tres convenciones centrales en esta materia: i) la Convención de las Naciones Unidas contra la Delincuencia Organizada Trasnacional de Palermo, ii) la Convención Interamericana contra la Corrupción y iii) Convención de Naciones Unidas contra la Corrupción ${ }^{(25)}$. De los cuales destaca la última, al ser la más completa y la que desarrolla estándares más exigentes (Bregaglio 2015, 119).

El fenómeno de la corrupción, al ser muy complejo y sumamente dañino para la sociedad bajo distintos aspectos, necesita que se uniformicen los criterios para hacerle frente, es por ello que los Estados se han preocupado por suscribir diversos instrumentos internacionales que fijen pautas (Bregaglio 2015, 130). A criterio de San Martín, incluso, se debe de entender a la corrupción como un "crimen de Estado", que no puede tener el mismo tratamiento que los delitos comunes, sino que amerita uno especial, como el que se plasma en estos parámetros internacionales (2012, 42-46), que de forma soberana, hemos asumido.

Este régimen internacional impone que la política del Estado en contra de la corrupción, debe realizarse -principalmentede acuerdo a los siguientes estándares: i) concepción amplia de corrupción, ii) concepción amplia de funcionario público, iii) criminalización de formas anticipadas de intervención delictiva, iv) ampliación del plazo de prescripción de la acción penal, v) los elementos subjetivos de la conducta o del tipo legal, podrán inferirse de las circunstancias fácticas objetivas, vi) imposición de responsabilidad a las personas jurídicas por su participación en los delitos, independientemente de la responsabilidad individual de las personas naturales, vii) jurisdicción amplia de la persecución de los delitos, y viii) promoción de la recuperación de activos e implementación de políticas que impidan los ingresos indebidos (San Martín 2012, 42-47).

Estos parámetros están orientados a promover la persecución amplia y efectiva de la corrupción, con herramientas especiales de Derecho penal y Procesal penal, dada la complejidad de dicho fenómeno y sus nocivos efectos en los derechos fundamentales de las personas. Razón por la cual, son importantes, necesarios y nos someten a la fiscalización internacional de su cumplimiento (San Martín 2012, 42).

La lucha contra la corrupción es un mandato constitucional que se desprende de los artículos 39, 41 y 44 de nuestra Constitución, conforme ha sido reconocido por el Tribunal Constitucional en las STC 006-2006-PCC/TC y 00017-2011-PI/TC. $Y$ en virtud a ello, nuestro país no solo ha suscrito los instrumentos internacionales a los que hemos hecho referencia, sino que también ha reiterado su compromiso de lucha contra la corrupción en diversos espacios internacionales $^{(26)}$ y se ha comprometido a la ejecución de los Objetivos de Desarrollo Sostenible de la Organización de Naciones

(25) El Perú ratificó este tratado el 16 de noviembre de 2004, mediante Decreto Supremo № 075-2004-RE. Bregalio resalta que los instrumentos internacionales en materia de corrupción que ha suscrito nuestro país no solo se limitan a los tratados antes descritos, que son "acuerdos entre dos o más Estados destinados a producir efectos jurídicos en el Derecho Internacional"; sino que también ha suscrito Actos concertados no convencionales, que si bien "reflejan un acuerdo entre Estados (...) por propio acuerdo de dichos Estados, no resultan vinculantes". Desde el año 1990, el Perú ha suscrito los siguientes instrumentos del soft law relacionados a la lucha contra la corrupción: i)Declaración sobre la cooperación internacional para la prevención del delito y la justicia penal en el contexto de desarrollo (1990), ii) Declaración de la Organización de las Naciones Unidas sobre la corrupción y el soborno de las transacciones comerciales internacionales (1996), iii) Código internacional de conducta para los funcionarios o titulares de cargos públicos (1997), iv) Declaración de Quito sobre desarrollo social y democracia frente a la incidencia de la corrupción (2004) . Véase: Renata Bregaglio Lazarte. "La lucha contra la corrupción en el Ordenamiento Internacional", en Aproximación multidisciplinaria para el procesamiento de casos de corrupción en el Perú. (Lima: Idehpucp - USAID, 2015), 116-118.

(26) Como en la Organización para la Cooperación y Desarrollo Económicos (OCDE), el Foro Económico Asía Pacifico (APEC), Comunidad de Estados Latinoamericanos y Caribeños (CELAC), Cumbre de las Américas, entre otros. 
Unidas, entre los que destaca "Promover sociedades pacíficas e inclusivas para el desarrollo sostenible, facilitar el acceso a la justicia para todos y crear instituciones eficaces, responsables e inclusivas a todos los niveles" (objetivo 16), para lo cual se busca, entre otras metas, reducir sustancialmente la corrupción y el soborno en todas sus formas, y crear instituciones eficaces, responsables y transparentes a todos los niveles ${ }^{(27)}$.

En esta misma línea, a nivel comunitario andino, el Perú ha suscrito los siguientes instrumentos ${ }^{(28)}$ :

- Las Líneas Directrices de la OCDE para empresas multinacionales del año 2000, que promueven el emprendimiento de acciones positivas en las empresas para enfrentar diversos problemas de la sociedad como la corrupción, que es concebida desde un punto de vista amplio, pues incluye la prevención de los actos de corrupción privada ${ }^{(29)}$. El Perú, como gobierno adherente de la Declaración de la OCDE sobre Inversión Internacional y Empresas Multinacionales, debe impulsar estas directrices en las empresas que se desarrollan en su territorio.

- El Pacto Mundial de Naciones Unidas, del 26 de julio de 2000, que busca promover la responsabilidad empresarial a través de 10 principios ${ }^{(30)}$, entre los cuales se encuentra el que "las empresas trabajen contra la corrupción en todas sus formas, incluidas extorsión y soborno(31)".

- La Decisión 668 de la Comunidad Andina, que en el año 2013 estableció el Plan Andino de Lucha contra la Corrupción, a fin de implementar políticas, mecanismos y estrategias para que sus miembros enfrenten este fenómeno complejo, entre las cuales se encuentra la promoción de mecanismos de autorregulación para la prevención de la corrupción en el sector privado ${ }^{(32)}$.

Tales instrumentos internacionales no se limitan a enfrentar solo la corrupción pública, sino que han reconocido la importancia que puede tener en este fenómeno la acción del sector privado, cuya actividad también debe ceñirse al respeto de las normas éticas. Y de todos ellos, la Convención de Naciones Unidas contra la Corrupción del 2004 sintoniza con la manera cómo se ha tipificado la corrupción en el ámbito privado en nuestro país (artículo 241-A), toda vez que, en ese instrumento internacional, se indicó lo siguiente:
"Cada Estado Parte considerará la posibilidad de adoptar las medidas legislativas y de otra índole que sean necesarias para tipificar como delito, cuando se cometan intencionalmente en el curso de actividades económicas, financieras o comerciales: a) La promesa, el ofrecimiento o la concesión, en forma directa o indirecta, a una persona que dirija una entidad del sector privado o cumpla cualquier función en ella, de un beneficio indebido que redunde en su propio provecho o en el de otra persona, con el fin de que, faltando al deber inherente a sus funciones, actué o se abstenga de actuar, b) La solicitud o aceptación, en forma directa o indirecta, por una persona que dirija una entidad del sector privado o cumpla cualquier función en ella, de un beneficio indebido que redunde en su propio provecho o en el de otra persona, con el fin de que, faltando al deber inherente a sus funciones, actúe o se abstenga de actuar" (artículo 21 de la CNUCC).

La tipificación de la corrupción en el sector privado, entonces, se encuentra en sintonía con los distintos instrumentos internacionales a los que hemos hecho referencia, que buscan enfrentar la corrupción de forma más eficiente en una economía globalizada como la que tenemos y en donde el sector privado puede coadyuvar -a través de su actividada crear espacios de corrupción, que también debemos prevenir como Estado.

\subsection{Contexto nacional}

Hemos visto distintos instrumentos internacionales donde se menciona la importancia de que cada país ofrezca una contención de carácter penal frente a los perniciosos efectos que involucra los actos

(27) Punto II de la Política nacional de Lucha contra la Corrupción. Disponible en: http://can.pcm.gob.pe/wp-content/uploads/2017/09/D.S.N\%C2\%B0-092-2017-Pol\%C3\%ADtica-Nacional-de-Integridad-y-Lucha-contra-la-Corrupci\%C3\%B3n.pdf.

(28) Fernando Jimenez Valderrama y Lourdes García Rodríguez, "El interés jurídico protegido en el delito de corrupción privada en Colombia. Análisis de contexto y conexiones con el derecho de la competencia desleal”, IUS Revista del Instituto de Ciencias Jurídicas de Puebla 35, Año IX(2015), 168.

(29) Ver Líneas directrices de la OCDE para empresas multinacionales. (OCDE: OECD Publishingp, 2011) 51-54. Recuperado de internet: https://www.oecd.org/daf/inv/mne/MNEguidelinesESPANOL.pdf (consultado el 01 de marzo de 2018).

(30) Derivados de varios tratados internacionales, de los que el Perú es Parte, como la Convención de Naciones Unidas Contra la Corrupción.

(31) Véase: https://www.pactomundial.org/category/aprendizaje/10-principios/.

(32) Véase: http://www.comunidadandina.org/DocOficialesFiles/Gacetas/Gace1509.pdf. 
Análisis de la tipificación de la corrupción privada en el Perú: ¿Una estrategia global contra la corrupción también debe involucrar a los particulares? ¿Y a las empresas?

An Analysis of the Criminal Typification of Private Corruption in Peru: Should a global strategy against corruption involve the private sector? And what about companies?

de corrupción que se realizan no solo en el sector público, sino también en el sector privado, en aras de enfrentar este fenómeno criminal de forma eficiente. En el plano nacional, ello se ha plasmado en dos documentos fundamentales: i) La Política Nacional de Integridad y Lucha contra la corrupción, aprobado mediante Derecho Supremo 092-2017-PCM del 14 de setiembre de 2017; y ii) El Plan Nacional de Integridad y Lucha contra la Corrupción 2018-2021, aprobado mediante Decreto Supremo 044-2018-PCM, del 26 de abril de 2018.

La consolidación de estos documentos base, conforme el propio Plan Nacional de Integridad y Lucha contra la Corrupción 2018-2021 lo reconoce, se erigen principalmente en función de los siguientes documentos ${ }^{(33)}$ :

El Informe de la Comisión Presidencial de Integridad( ${ }^{(34)}$, de diciembre de 2016, donde se advirtió que "el sector privado juega un rol clave en nuestro desarrollo económico y social. El riesgo de corrupción atenta contra el desarrollo sostenible del país y afecta a las propias empresas. La promoción de la integridad y la lucha contra la corrupción requieren del trabajo conjunto del Estado y del sector privado, a través de la implementación de programas de prevención, incentivos y sanciones efectivas"(35).

El Estudio de la OCDE sobre Integridad en el Perú que exhortó a nuestro país a implementar un sistema integral que construya una cultura de integridad, dejando de lado el enfoque reactivo que hasta ese momento tenía( ${ }^{(36)}$. La OCDE resaltó que para llevar a cabo dicha tarea requería de un esfuerzo coordinado en todo el sector público y también del privado(37).

Las 100 acciones para forjar un país sin corrupción que el Fiscal de la Nación Pablo Sánchez presentó en junio de 2017, donde propuso, entre otras medidas, sancionar la corrupción privada ${ }^{(38)}$ y adjuntó como anexo a dicho documento una propuesta legislativa en ese sentido ${ }^{(39)}$. El ex Fiscal de la Nación fundamentó esta acción sobre la base de que "la cooperación y responsabilidad de la empresa es necesaria y constituye un elemento esencial en la prevención de la corrupción. Prevenir la corrupción en la actividad empresarial resulta, por tanto, clave no solo para reducir los índices de corrupción en el sector público, sino fundamentalmente también para contribuir a una competencia leal y en condiciones de igualdad entre los concurrentes"(40).

El Compromiso de Lima de la Cumbre de las Américas del 14 de abril de 2018, en el que nos comprometimos, entre otras cosas, a adoptar un marco legal para responsabilizar a las personas jurídicas por actos de corrupción, de conformidad con la Convención de Naciones Unidas contra la Corrupción y la Convención Interamericana contra la Corrupción, incluidos el cohecho interno e internacional, cuando no esté previsto en la legislación nacional(41).

Es por ello que en el Plan Nacional de Integridad y Lucha contra la Corrupción 2018-2021 se enfatiza que su labor incluye a las entidades del sector privado, a quienes exhorta a implementar mecanismos de prevención, acorde con lo establecido en la Ley 30424. Además de establecer como objetivo: la tipificación del delito de corrupción privada, en el Eje 3 de sus objetivos estratégicos y acciones para consolidar un marco normativo penal que evite toda laguna de impunidad(42).

Como puede advertirse, entonces, la necesidad del enfoque amplio del concepto de corrupción y de involucrar activamente a las organizaciones del sector privado en su prevención, forma parte de una respuesta integral en contra de este fenóme Estrategia que ha sido prevista tanto en los instrumentos del plano internacional, como en los desarrollados en el contexto nacional, donde se incluye también como medida la tipificación de la corrupción privada.

(33) Punto I del Plan de Lucha Nacional de Integridad y Lucha contra la Corrupción 2018-2021.

(34) Esta Comisión fue formada en el Gobierno del expresidente Pedro Pablo Kuczynky y elaboró un Informe con 100 recomendaciones para luchar contra la corrupción.

(35) Punto XII del Informe de la Comisión de Integridad.

(36) OCDE. Estudio de la OCDE sobre la Integridad en el Perú. Resultados y Recomendaciones, 3. Recuperado de internet: https:// www.oecd.org/gov/ethics/peru-estudio-integridad-folleto.pdf (consultada el 01 de marzo de 2019).

(37) OCDE. Estudio de la OCDE sobre la Integridad en el Perú. Resultados y Recomendaciones, 3.

(38) Medida 92, Pablo Sánchez Velarde. 100 acciones propuestas por el Fiscal de la Nación, 2017, 11.

(39) Pablo Sánchez Velarde. 100 acciones propuestas por el Fiscal de la Nación, 2017, 32-39.

(40) Pablo Sánchez Velarde. 100 acciones propuestas por el Fiscal de la Nación, 2017, 34.

(41) Acuerdo 35 del Compromiso de Lima de la Cumbre de las Américas. Disponible en: http://www.viiicumbreperu.org/compromiso-delima-gobernabilidad-democratica-frente-a-la-corrupcion/.

(42) Objetivo 51 del Eje 3 - Capacidad sancionadora del Estado Frente a los Actos de corrupción del Plan de Lucha Nacional de Integridad y Lucha contra la Corrupción 2018-2021. 
Dicho enfoque ya se había recogido también en la Exposición de Motivos del Proyecto de Ley 1265/2016-CR del 20 de abril de $2017^{(43)}$, donde se afirmó que la lucha contra la corrupción no debe distinguir entre agentes del sector público e individuos del sector privado, sino que debe partir de la idea de enfrentar la corrupción en general. Así, aquella iniciativa legislativa propuso "(...) eliminar una fuente de la corrupción, en la que intervienen personas del sector privado, razón por la cual la credibilidad, integridad y el profesionalismo son indispensables para combatir y hacer frente a la corrupción".

En la Exposición de Motivos del Proyecto de Ley 1773/2017MP, planteado por el ex Fiscal de la Nación Pablo Sánchez Velarde el 11 de agosto de 2017, también se compartió dicha perspectiva al sostenerse lo siguiente:

(...) la corrupción en el sector privado constituye uno de los mayores problemas necesitados de regulación en la sociedad peruana". Proponiéndose por ello la introducción en el Código Penal del delito de corrupción entre particulares, a fin de que se deje patente "la asunción de una estrategia global contra el fenómeno de la corrupción, ya no solo constreñida al ámbito de la función pública.

Si bien el Decreto Legislativo 1385 se emitió en el marco de delegación de facultades dadas mediante la Ley 30823 , de manera que no tiene como fuente directa al Proyecto de Ley 1773/2017-MP ni al Proyecto de Ley 1265/2016-CR, es importante mencionar que, tras la revisión de ambos planteamientos sobre la criminalización de la corrupción privada, se observa la existencia de una idea en común: la persecución y sanción de todas las formas de corrupción debe realizarse desde una estrategia integral que incluya la intervención del Derecho penal en el ámbito de la corrupción privada.

Aquello, a nuestro criterio, también sería la base del Decreto Legislativo 1385, que tiene como fuente a la Ley 30823 y, en específico, al literal c) del inciso 3 del artículo 2 del citado dispositivo legal que establece la facultad de legislar en materia de integridad y lucha contra la corrupción. Incluso, en el artículo 1 del Decreto Legislativo 1385, se indicó que el propósito de dicha norma es "sancionar penalmente los actos de corrupción cometidos entre privados que afectan el normal desarrollo de las relaciones comerciales y la competencia leal entre empresas", lo que nos permite colegir que una estrategia integral de persecución y sanción de la corrupción también debería comprender el plano de las personas jurídicas, toda vez que estás son consideradas como centros de generación de riesgos, en vista de que, en muchas ocasiones, pueden verse involucradas en actos ilícitos (ejemplo; actos de corrupción) durante el ejercicio de sus actividades.

Por ello mismo, la intervención del Derecho Penal no debería limitarse al castigo de la corrupción pública(44), pues las conductas de soborno en la contratación privada "(...) constituyen una forma de corrupción que debe ser atajada, si se quiere contar con un régimen de competencia libre y leal" (Encinar 2017, 52). La corrupción así entendida se percibe como una realidad que debe ser perseguida y sancionada penalmente, aun en una materia que se considera estrictamente privada, dadas las cualidades de los sujetos implicados y el objeto de los negocios jurídicos y contratos que suscriben (Encinar 2017, 52).

\section{La criminalización de la corrupción privada a través del Decreto Legislativo 1385}

El 04 de setiembre del 2018 se publicó, en el Diario Oficial El Peruano, el Decreto Legislativo 1385, mediante el cual se incorporaron los artículos 241- A y 241- B dentro del Título IX del Código Penal, con el propósito de criminalizar los actos de corrupción entre privados que se cometan en las relaciones comerciales (artículo 241A) y los comportamientos desleales que provoquen un perjuicio a la persona jurídica (artículo 241-B).

En el artículo 1 del Decreto Legislativo 1385 se indica que el objeto de la criminalización

(43) Presentado por el Congresista de la Republica Héctor Becerril Rodríguez.

(44) El citado autor es de la idea de que en las relaciones entre privados también pueden existir intereses públicos que pueden ser afectados, toda vez que aquello no se limita al plano estrictamente público. En concreto, Montoya sostiene lo siguiente: "Como respuesta se dice que en el primer caso estamos ante un funcionario público y se protege un interés público que es el correcto ejercicio de la función pública. Pues bien, si consideramos que un club de futbol o un colegio (aunque sea particular) son entidades sobre las cuales existe un directo interés público que trasciende, por lo tanto, el interés de los socios o sus fundadores, entonces, no debería haber duda para que el Estado sancione penalmente estos casos. Yvan Montoya Vivanco. "¿Por qué no penalizar la corrupción privada?”, Proyecto Anticorrupción, Boletín 10, marzo, 2012. Recuperado de internet: http://cdn01.pucp.education/ idehpucp/wp-content/uploads/2017/06/30213651/2012_boletin10.pdf (consultada el 07 de febrero de 2019). 
Análisis de la tipificación de la corrupción privada en el Perú: ¿Una estrategia global contra la corrupción también debe involucrar a los particulares? ¿Y a las empresas?

An Analysis of the Criminal Typification of Private Corruption in Peru: Should a global strategy against corruption involve the private sector? And what about companies?

es "(...) sancionar penalmente los actos de corrupción cometidos entre privados que afectan el normal desarrollo de las relaciones comerciales y la competencia leal entre empresas", lo que encuentra respaldo en una noción amplia de corrupción, que traspasa la tradicional incriminación y sanción de la corrupción pública para incidir en un escenario donde las partes que intervienen son particulares.

Lo indicado es sumamente importante, pues el legislador, o quien quiera aplicar la norma penal en un caso concreto, debe señalar las razones que legitiman la prohibición de un comportamiento, toda vez que se trata de una restricción al ámbito de libertades reconocidas a los ciudadanos. Así, para evidenciar que no se trata de un hecho de fuerza, sino que supone el empleo racional y justificado del poder (Palomino 2017, 29), se deberá "analizar la idoneidad y necesidad de restringir la libertad de actuación para proteger el bien jurídico, y si la forma en que se restringe la libertad es adecuada de cara a dicha protección" (Meini 2014, 33).

Entonces, podrá afirmarse que la restricción de la libertad de actuación fue justa, si es que, de cara a la protección de un determinado bien jurídico, se superaron las exigencias del test de proporcionalidad (Meini 2014, 33). De ser esto así, la ley no será una mera disposición de voluntad, sino, sobre todo, disposición de la razón, al punto que, como indica Sánchez, podrá hablarse de un "orden captado por la razón humana que permite hacer Derecho y criticar sus pretendidas plasmaciones" (2012), 66.

Siendo esto así, cabe indicar que Lopera indica lo siguiente al respecto:

"En virtud del subprincipio de idoneidad sólo puede justificarse una medida a la luz de determinado fin si ésta en efecto contribuye a su consecución, pero no si resulta indiferente o incluso contraproducente de cara a la realización del fin propuesto. Con el subprincipio de necesidad, por su parte, se quiere poner freno a la tendencia a emplear los medios más contundentes, más invasivos, para alcanzar los objetivos legislativos de un modo pretendidamente más eficaz. Finalmente, el subprincipio de proporcionalidad en sentido estricto, al exigir que la libertad que se protege con la intervención del legislador no resulte inferior a la que se sacrifica, representa una clara concreción del principio de utilidad" $(2010,160)$.

Desde esa perspectiva, debe observarse que la criminalización de la corrupción privada guarda correspondencia con la línea seguida tanto en la Política Nacional de Integridad y Lucha contra la Corrupción como en el Plan Nacional de Lucha contra la Corrupción 2018 - 2021. Así, en el primero, se define corrupción como "El mal uso del poder público o privado para obtener un beneficio indebido; (...) por agentes públicos, privados o ciudadanos; vulnerando (...) normas y derechos fundamentales"(45); mientras que, en el citado Plan Nacional de Lucha contra la Corrupción, se precisa que uno de sus ámbitos de combate a la corrupción "involucra sin distinción a todas las entidades públicas, privadas, empresas, ciudadanía y colectivos sociales, los cuales deben implementar modelos de prevención (...)".

Asimismo, como hemos indicado, no solo existen diversos instrumentos internacionales como las Convención de las Naciones Unidas contra la Delincuencia Organizada Trasnacional, la Convención Interamericana contra la Corrupción o la Convención de Naciones Unidas contra la Corrupción que se encuentran orientados a promover una amplia persecución de dicho fenómeno criminal, sino que también existe un marco constitucional que reconoce la importancia de que el Estado peruano luche contra aquellas conductas socialmente nocivas.

Por todo ello, la criminalización o tipificación de la corrupción privada se trata de una medida que sí puede justificarse a la luz de un determinado fin: la persecución y sanción de aquellas formas de corrupción que alteran las reglas de la leal competencia en el mercado, que tienen como propósito que los bienes y servicios se ofrezcan en condiciones de competitividad abierta y libre (Bolea 2013, 10) ${ }^{(46)}$.

A mayor abundamiento, podría indicarse que el Decreto Legislativo 1385 considera que la proscripción de los actos de corrupción entre privados, al suponer un peligro intolerable para el normal desarrollo de las relaciones comerciales y la competencia leal entre empresas, es una parte importante de la estrategia global de persecución y sanción

(45) Véase: http://can.pcm.gob.pe/wp-content/uploads/2017/09/D.S.-N\%C2\%B0-092-2017-Pol\%C3\%ADtica-Nacional-de-Integridad-yLucha-contra-la-Corrupci\%C3\%B3n.pdf

(46) En estricto, la mencionada autora señala lo siguiente: "Si la corrupción se define en términos generales como un fenómeno que altera el normal funcionamiento de las instituciones, la corrupción privada tiende a explicarse como aquella forma de corrupción que viene a alterar el normal funcionamiento de las relaciones comerciales". 
de dicho fenóme Se amplía así el campo de intervención del Derecho penal que estuvo limitado solo a la represión de la corrupción pública, para pasar a un escenario donde se sanciona penalmente también el mal uso del poder privado para obtener un beneficio indebido en el marco de las relaciones comerciales. Por esto, es importante observar si dicha restricción de la libertad de actuación supera o no los subprincipios de necesidad y de proporcionalidad en sentido estricto.

\subsection{El delito de corrupción en el ámbito privado (Artículo 241-A)}

La fórmula típica del delito de corrupción en el ámbito privado (artículo 241-A) es similar a la de los delitos de cohecho pasivo y cohecho activo en el contexto de los ilícitos penales contra la Administración Pública, toda vez que, la corrupción en el ámbito privado, da cuenta también de dos modalidades para dar lugar al hecho típico: corrupción pasiva y corrupción activa. La primera modalidad está dirigida a los socios, accionistas, gerentes, directores, etc. de la persona jurídica; mientras que, la segunda, es decir, la corrupción pasiva, se dirige al individuo que compra el "servicio" o recibe el ofrecimiento del funcionario de la empresa.

Dicho esto, siguiendo a Meini, es preciso indicar que la "identificación del bien jurídico demanda siempre una interpretación teleológica de la ley penal que tenga en cuenta los principios del derecho penal" $(2014,34)$. García, por su lado, indica que cada ley tiene un fin de regulación, cuya determinación obliga a recurrir "(...) a una teoría objetiva (voluntad de la ley), sin dejar de lado obviamente la conexidad o correspondencia con los criterios subjetivo e histórico. Elementos de juicio para esta constatación objetiva de la voluntad de la norma son su denominación legislativa, el tenor literal, y sobre todo su ubicación sistemática" $(2012,286)$.

Así las cosas, el delito de corrupción privada se encuentra previsto en el artículo 241- A se ubica dentro del Título IX del Código Penal, esto es, dentro del marco de los delitos contra el orden económico. Sin embargo, de acuerdo al artículo 1 del Decreto Legislativo 1385, la finalidad de la incorporación de los artículos 241-A y 241-B es sancionar penalmente los actos de corrupción cometidos entre privados que afecten el normal desarrollo de las relaciones comerciales y la competencia leal entre empresas. Lo que, a nuestro criterio, apunta a que el bien jurídico sea la leal competencia, sobre todo si, como hemos visto, la Exposición de Motivos de los proyectos de ley dan una idea clara de la intención del legislador; el Decreto Legislativo 1385 se promulgó en virtud de la Ley 30823 , que delegó en el Poder Ejecutivo la facultad de "incorporar en el Código Penal los delitos de corrupción en el sector privado que atenten contra la libre y leal competencia empresarial"; y, además, la literalidad del tipo define un determinado contexto típico: la adquisición o comercialización de bienes, la contratación de servicios comerciales y las relaciones comerciales.
En efecto, en ambas modalidades de corrupción (pasiva/activa) lo que se afecta son las reglas de la leal competencia en el mercado que tienen como propósito que los bienes y servicios se ofrezcan en condiciones de competitividad abierta y libre. El contexto típico del delito de corrupción en el ámbito privado permite sostener ello, ya que será en la adquisición o comercialización de bienes o mercancías, en la contratación de servicios comerciales o en las relaciones comerciales donde se favorecerá a otro a consecuencia del beneficio indebido que acepta, recibe o solicita un miembro de la alta dirección, trabajador o asesor de una persona jurídica, a partir de lo cual el resto de los competidores se verán indebidamente desplazados.

Se trata, pues, de un comportamiento socialmente disfuncional que supone un intenso riesgo para las condiciones de competitividad en la oferta de bienes y servicios, que debe ser abierta y libre, toda vez que es de suma importancia para el éxito del modelo económico; razón por la cual, en el artículo 61 de nuestra Constitución Política, se impone al Estado el deber de facilitar y vigilar la libre competencia, encontrándose, además, obligado a castigar toda práctica que la limite indebidamente (García Cavero 2015, 42).

En ese sentido, en el Perú la protección de la competencia se realiza tanto de manera administrativa como penal. Sobre esto último, desde una perspectiva funcionalista del Derecho penal, García indica lo siguiente:

“(...) los delitos contra la libre competencia protegen la expectativa normativa de los agentes económicos de poder participar en el mercado sin restricciones artificiales creadas por otros participantes. Su defraudación requiere cierto nivel de afectación al esquema de orientación de los intervinientes en el mercado por parte de quienes cuentan con el poder de imponer sus propios intereses" $(2015,52)$.

Por su lado, Bolea - comentando la norma española de corrupción privadaseñala al respecto:

“(...) lo que se intenta proteger a través de este nuevo delito es la afectación de la competencia ad extra y ad intra, esto es: por un lado, el interés de los terceros 
Análisis de la tipificación de la corrupción privada en el Perú: ¿Una estrategia global contra la corrupción también debe involucrar a los particulares? ¿Y a las empresas?

An Analysis of the Criminal Typification of Private Corruption in Peru: Should a global strategy against corruption involve the private sector? And what about companies?

competidores en no quedar desplazados por ofertas claramente peores que, sin embargo, son preferidas por venir acompañadas de incentivos, beneficios o ventajas; $y$, por otro, el interés de la propia empresa en que el encargado adquiera bienes o servicios que constituyan la mejor oferta en el mercado" $(2013,13)$.

En cambio, para Faraldo se tutelarían los "intereses económicos legítimos de los empresarios competidores, que constituyen un bien jurídico individual de contenido económico, pero con la particularidad de que su tutela se orienta a la protección de un bien jurídico mediato supraindividual, la competencia leal, que es lesionado ya al ponerse en peligro abstracto el bien jurídico individual"(47).

En la experiencia comparada, Gili comenta que en Alemania "fueron razones preventivo generales, tendentes a reforzar la conciencia de la población en cuanto a que la corrupción en el ámbito comercial afectaba no sólo a las empresas, sino que constituía un comportamiento socialmente dañoso, las que animaron al legislador a su traslado al Código penal" (2007, 11). De igual manera, García Cavero indica que "(...) el sistema de protección asumido por el Derecho alemán hasta antes de 1997 [era el de una protección limitada al Derecho administrativo], año en el que se dio la Ley de lucha contra la corrupción. Mediante esta ley se incluyó en el Código penal germánico un capítulo de delitos contra la competencia (...)" $(2015,42)$.

Por nuestro lado, consideramos que, en el delito de corrupción en el ámbito privado, es el soborno aceptado, recibido o solicitado por algún miembro de la alta dirección, trabajador o asesor (o prometido, ofrecido o concedido por un individuo que actúe en nombre de una persona jurídica que busca, por ejemplo, adjudicarse un contrato con la empresa donde el agente es miembro de la alta dirección, trabajador o asesor) lo que defrauda la expectativa normativa de poder participar en el mercado sin restricciones artificiales creadas por otros participantes.

En otras palabras, si la corrupción puede definirse de manera amplia como un fenómeno que altera el normal funcionamiento de las instituciones, entonces, es razonable señalar que la corrupción privada es aquella que altera las reglas de la leal competencia en el mercado, que tienen como propósito que los bienes y servicios se ofrezcan en condiciones de competitividad abierta y libre ${ }^{(48)}$, cuya tutela es importante para garantizar el legítimo interés de los competidores de participar bajo condiciones equitativas, lo que -conforme a los diversos instrumentos nacionales e internacionales que guían el combate del fenómeno de la corrupción- también es parte de la estrategia integral de persecución y sanción de todas las formas de corrupción.

Por ello mismo, la puesta en riesgo de dicho bien jurídico deberá trascender de meras disputas contractuales carentes de relevancia penal, a fin de legitimar la intervención del Derecho penal. Será determinante entonces que el comportamiento del agente presente la ofensividad necesaria para calificarse como un riesgo intolerable para el bien jurídico que es objeto de tutela, de manera que cualquier trivialidad quede al margen del alcance del tipo penal, aun cuando, para la consumación del mencionado delito, no se necesite demostrar la existencia de un perjuicio efectivo para los intereses económicos legítimos de los empresarios competidores.

En síntesis, consideramos que la tipificación de la corrupción privada (artículo 241- A) es una decisión legislativa que se justifica de cara a un fin: la persecución y sanción de aquellas formas de corrupción que alteran las reglas de la leal competencia en el mercado. Luego, también se trata de una medida necesaria, ya que la corrupción es un fenómeno social complejo, donde la intervención del Derecho penal es necesaria, pues las conductas de soborno en la contratación privada también "(...) constituyen una forma de corrupción que debe ser

(47) Patricia Feraldo Cabana. "Hacia un delito de corrupción en el sector privado" (conferencia elaborada para el "Il Congreso HispanoItaliano de Derecho penal económico, celebrado los días 21 al 23 de setiembre de 2000, en Paiva), 72. La mencionada autora, en relación con la tutela mediata e inmediata de bienes jurídicos a través de la criminalización de la corrupción privada, sostiene que: “(...) el orden económico en sentido amplio concebido como la regulación jurídica de la producción, distribución y consumo de bienes y servicios, se configura como un bien jurídico mediato que se sitúa detrás del bien jurídico individual inmediatamente protegido, los intereses económicos legítimos de los empresarios competidores. Es el bien jurídico inmediato el que sirve de principal referencia a la hora de descubrir el sentido y finalidad de los delitos que nos ocupan en el marco de la interpretación teleológica (...)". Patricia Feraldo Cabana, "Hacia un delito de corrupción en el sector privado" (conferencia elaborada para el "Il Congreso Hispano- Italiano de Derecho penal económico, celebrado los días 21 al 23 de setiembre de 2000, en Paiva), 73.

(48) Carolina Bolea Bardon . "El delito de corrupción privada. Bien jurídico, estructura típica e intervinientes", Indret: Revista para el Análisis del Derecho 2, marzo 2013,10. En estricto, la mencionada autora señala lo siguiente: "Si la corrupción se define en términos generales como un fenómeno que altera el normal funcionamiento de las instituciones, la corrupción privada tiende a explicarse como aquella forma de corrupción que viene a alterar el normal funcionamiento de las relaciones comerciales". 
atajada, si se quiere contar con un régimen de competencia libre y leal" (Encinar 2017, 52), más aun en el actual contexto que atraviesa nuestro país, a raíz del descubrimiento de prácticas corruptas arraigadas desde hace años en el sector privado, que no habrían podido ser prevenidas ni adecuadamente sancionadas a través de otras ramas del sistema jurídico, dado lo intenso de su nocividad social.

Se trata, finalmente, de una medida proporcional, toda vez que, el coste de la intervención penal, expresada en la limitación de derechos que supone, no será mayor al beneficio que puede conseguirse (Mir Puig 2009), en vista de que la conducta prohibida está acotada a la realización de actos corruptos en contextos específicos, que permiten diferenciar dicha acción de otras socialmente adecuadas.

\subsubsection{Primera modalidad: La corrupción privada pasiva (Primer} Párrafo del Artículo 241-A):

"El socio, accionista, gerente, director, administrador, representante legal, apoderado, empleado o asesor de una persona jurídica de derecho privado, organización no gubernamental, asociación, fundación, comité, incluidos los entes no inscritos o sociedades irregulares, que directa o indirectamente acepta, reciba o solicita donativo, promesa o cualquier otra ventaja o beneficio indebido de cualquier naturaleza, para sí o para un tercero para realizar u omitir un acto que permita favorecer a otro en la adquisición o comercialización de bienes o mercancías, en la contratación de servicios comerciales o en las relaciones comerciales, será reprimido con pena privativa de libertad no mayor de cuatro años e inhabilitación conforme al inciso 4 del artículo 36 del Código Penal y con ciento ochenta a trescientos sesenta y cinco días-multa".

Mediante el primer párrafo del artículo 241-A CP se castiga la corrupción privada pasiva, esto es, que la incriminación se dirige únicamente a una de las partes que interviene en el acto de corrupción: los miembros de la alta dirección, trabajadores o asesores de una persona jurídica.

Por tanto, el sujeto activo de este delito no puede ser cualquier individuo, sino uno que posea ciertas características especiales que lo vinculen con la persona jurídica como ser un socio, accionista, gerente, director, administrador, representante legal, apoderado, empleado o asesor. La persona jurídica puede ser de derecho privado, así como una organización no gubernamental, una asociación, fundación, comité e, incluso, podría tratarse también de entes no inscritos o sociedades irregulares.
Lo importante es que quien acepta, recibe o solicita el soborno tenga una determinada vinculación con la persona jurídica que le permita favorecer a otro en determinadas situaciones: i) adquisición o comercialización de bienes o mercancías; ii) contratación de servicios comerciales; iii) relaciones comerciales. No se exige que el agente realice el comportamiento prohibido por razón de su cargo en la persona jurídica, sin embargo, consideramos que las atribuciones del rol del agente deberían conducir a que pueda realizar $u$ omitir un acto que permita favorecer a otro; pues de lo contrario, no se configuraría una amenaza al objeto de protección del artículo 241-A CP.

Asimismo, para que se configure el delito de corrupción privada pasiva es necesario que el agente acepte, reciba o solicite un donativo, promesa o cualquier otra ventaja o beneficio indebido. El verbo aceptar implica que el agente admita, tolere o consienta aquello, sin ser necesario, de cara al perfeccionamiento de la conducta prohibida, que luego realice u omita un acto que permita favorecer a otro. Por recibir se entiende el hecho de embolsar, tomar o acoger algo, de manera que aquí tampoco se exige que el agente, pese a haber recibido el donativo o cualquier otra ventaja o beneficio indebido, realice u omita un acto que permita favorecer a otro. Por su parte, solicitar supone que el agente pida, procure o requiera la entrega de un donativo o cualquier otra ventaja o beneficio indebido, lo que basta para el perfeccionamiento del comportamiento típico(49).

En esa línea, cabe indicar que el sujeto activo puede aceptar, recibir o solicitar el soborno de manera directa o indirecta y en beneficio propio o de un tercero. En otras palabras, el agente puede aceptar, recibir o solicitar el soborno directamente o mediante una persona interpuesta. El beneficio obtenido puede ser para el funcionario, cualquier tercero o, inclusive, para la propia persona jurídica a que está vinculado(50). Si esto último

(49) Esta interpretación es la que ha seguido en el ámbito de los delitos contra la administración pública. Al respecto véase: Ramiro Salinas Siccha. 2017. Delitos contra la Administración Pública, 4ta edición (Lima: Grijley), 515 - 526.

(50) Ver al respecto: Estudio Rodrigo Elias \& Medrano Alerta Cumplimiento Normativo. Decreto Legislativo 1385 - Decreto Legislativo que sanciona la corrupción en el ámbito privado, 2018. Recuperado de internet: https://www.estudiorodrigo.com/alerta-cumplimientocorporativo-4/ (consultada el 01 de marzo de 2019). 
Análisis de la tipificación de la corrupción privada en el Perú: ¿Una estrategia global contra la corrupción también debe involucrar a los particulares? ¿Y a las empresas?

An Analysis of the Criminal Typification of Private Corruption in Peru: Should a global strategy against corruption involve the private sector? And what about companies?

fuera así, podríamos encontrarnos en un escenario donde dicha persona jurídica no habría tenido los mecanismos adecuados para mitigar el riesgo de que alguno de sus funcionarios incurra en el delito de corrupción privada pasiva (artículo 241-A CP)(51).

Otro aspecto importante es que del tenor literal del artículo 241-A CP se aprecia que solo se sanciona el acto de aceptar, recibir o solicitar un beneficio indebido que se encuentra dirigido a conseguir una determinada finalidad: que el funcionario de la persona jurídica realice $u$ omita un acto que favorezca a otro en la adquisición o comercialización de bienes o mercancías, en la contratación de servicios comerciales o en las relaciones comerciales.

Esta finalidad define entonces una estructura típica determinada, en cuya virtud el soborno debe aceptarse, recibirse o solicitarse antes de que pueda materializarse el propósito que se persigue. Por tanto, a diferencia de los delitos de cohecho pasivo que contemplan una modalidad subsecuente (arts. 393 y 394 CP), el delito regulado en el artículo 241-A $\mathrm{CP}$ no prevé semejante modalidad, de manera que aceptar, recibir o solicitar una ventaja indebida a cambio de haber realizado u omitido un acto que permita favorecer a otro será un comportamiento atípico.

El artículo 241-A CP tampoco exige que el agente acepte, reciba o solicite un beneficio indebido para realizar $u$ omitir un acto en violación de sus obligaciones o sin faltar a aquellas, sino que basta con que el comportamiento del sujeto activo permita favorecer a otro en el marco de las mencionadas situaciones contextuales típicas. Se diferencia así de las clásicas figuras cohecho que sancionan "al funcionario que recibe, acepta o solicita recibir de una persona una ventaja o beneficio de cualquier índole a cambio de realizar algún acto conforme [cohecho pasivo impropio] o contrario [cohecho pasivo propio] a sus funciones públicas" (Montoya 2015, 95).

No obstante, cabe mencionar que, en el artículo 21 de la Convención de las Naciones Unidas contra la Corrupción, al indicarse que cada Estado Parte deberá considerar la posibilidad de criminalizar la corrupción privada, se planteó que la conducta prohibida se trate de alguna que implique una falta al deber inherente a las funciones del agente. Pese a ello, en el artículo 241-A CP no se precisa dicha exigencia, sino que es suficiente con que se realice $u$ omita un acto que permita favorecer a otro, por lo que da igual si se hace con violación de sus obligaciones o sin faltar a aquellas, lo que interesa es que exprese un mal uso del poder privado ${ }^{(52)}$.

De otro lado, cabe indicar que el soborno no tiene que ser necesariamente de naturaleza patrimonial o económica. El soborno puede ser de cualquier naturaleza y puede ser que el socio, accionista, gerente, director, etc. lo reciba para sí o para un tercero. Lo importante es que la recepción o solicitud del soborno se realice a cambio de un acto dirigido a favorecer a otro y que sea idóneo para influir en la decisión del agente.

Ahora bien, la idoneidad del soborno debería conducir a que se descarten "las meras atenciones", siempre, claro está, que no exista una evidente desproporción entre el obsequio o cortesía y el acontecimiento que lo amerita, lo que deberá valorarse de acuerdo al concreto contexto de interacción donde se realiza la conducta, a fin de que no represente un soborno disfrazado(53). Será necesario, entonces, acudir a los criterios de la imputación objetiva, así como al conjunto de principios del Derecho penal, para acotar razonablemente el alcance del delito de corrupción en el ámbito privado.

Respecto a la realización u omisión de un acto que se oriente al favorecimiento de otro en cualquiera de las situaciones típicas descritas líneas arriba, es razonable sostener que aquello puede abarcar tanto a una persona natural como a una persona

(51) No obstante, si el agente actúa en beneficio propio o de un tercero distinto a la persona jurídica a la cual se encuentra vinculado, es evidente que nos encontraríamos en un contexto de infracción de deberes de lealtad hacia la empresa para la que aquel individuo trabaja, por lo que, aun si la Ley 30424 se ampliase al punto de abarcar el delito de corrupción en el ámbito privado, en aquel supuesto la empresa no tendría responsabilidad alguna, toda vez que el comportamiento realizado no sería en su beneficio sino todo lo contrario. Al respecto puede verse: Carolina Bolea Bardon. "El delito de corrupción privada. Bien jurídico, estructura típica e intervinientes", Indret: Revista para el Análisis del Derecho 2, marzo 2013, 6.

(52) No es necesario que se realice un supuesto de administración desleal, esto es, que se incumplan los deberes de un administrador leal (obligaciones ad intra) ni que necesariamente se afecte el interés (patrimonial o no) de la empresa a la cual se encuentra vinculado. Sobre la inexistencia de una unión indisoluble entre la administración desleal y la constatación de corrupción privada. Puede verse: Carlos Gómez Jara. 2008. "Corrupción en el sector privado: ¿competencia desleal y/o administración desleal?”. Revista cuatrimestral de las Facultades de Derecho y Ciencias Económicas y Empresari+iales n. ${ }^{\circ}$ 74, mayo-agosto, 234 - 241.

(53) En sentido similar, aunque referido en concreto a los actos de corrupción en el ámbito público, puede verse: Manuel Abanto Vásquez. Los delitos contra la Administración Pública en el Código Penal peruano (Lima: Palestra Editores, 2001), 384. 
jurídica(54). Por ejemplo, podría darse el caso de que el soborno este dirigido a beneficiar a una persona jurídica que busca adjudicarse un contrato con la empresa donde el agente es socio, accionista, gerente, director, administrador, representante legal, apoderado, empleado o asesor.

En un escenario así, las victimas serían los competidores afectados por las decisiones de contratación de bienes o servicios que se adoptaron en clave de contraprestación por los beneficios indebidos aceptados, recibidos o solicitados, por parte de aquellos cuyo rol les posibilita realizar u omitir un acto que permita favorecer a otro, esto es, por quienes dentro de una empresa tienen capacidad de influir en tal decisión ${ }^{(55)}$.

Brevemente, el comportamiento prohibido consiste en que el agente (los miembros de la alta dirección, trabajadores o asesores de una persona jurídica) acepte, reciba o solicite (verbos rectores) un beneficio indebido (dinero o cualquier otro medio corruptor) a cambio de realizar $u$ omitir un acto que se oriente al favorecimiento de otro (que puede ser una persona natural o jurídica) en la adquisición o comercialización de bienes o mercancías o en la contratación de servicios comerciales o en las relaciones comerciales (contexto típico). El comportamiento es evidentemente de carácter doloso.

La tramitación de este delito es de acción pública, es decir, que su persecución se encontrará a cargo del Ministerio Público, el cual podrá intervenir de oficio o a partir de la denuncia interpuesta por cualquier persona.

4.1.2. Segunda modalidad: La corrupción privada activa (Segundo Párrafo del Artículo 241 - A):

(...) Será reprimido con las mismas penas previstas en el párrafo anterior quien, directa o indirectamente, prometa, ofrezca o conceda a accionistas, gerentes, directores, administradores, representantes legales, apoderados, empleados o asesores de una persona jurídica de derecho privado, organización no gubernamental, asociación, fundación, comité, incluidos los entes no inscritos o sociedades irregulares, una ventaja o beneficio indebido de cualquier naturaleza, para ellos o para un tercero, como contraprestación para realizar u omitir un acto que permita favorecer a éste u otro en la adquisición o comercialización de bienes o mercancías, en la contratación de servicios comerciales o en las relaciones comerciales.
De acuerdo al segundo párrafo del artículo 241-A no se exige ninguna característica especial en el sujeto activo de cara a la realización del hecho delictivo. Por ello mismo, cualquier individuo que prometa, ofrezca o conceda una ventaja o beneficio indebido de cualquier naturaleza a alguno de los sujetos indicados en el primer párrafo del artículo 241-A, con la finalidad de que se realice $u$ omita un acto que permita que se le favorezca a él u otro en la adquisición o comercialización de bienes o mercancías, así como en la contratación de servicios comerciales o en las relaciones comerciales, será un potencial autor del citado ilícito penal.

La conducta descrita puede realizarse de manera directa o indirecta. Lo importante es que se lleve a cabo con el propósito de que se realice u omita un acto que permita favorecer al propio agente $u$ otro. Por otro puede comprenderse tanto a una persona natural o jurídica, toda vez que el contexto donde se realizará dicha conducta no descarta la posibilidad de que el agente actúe en nombre y en beneficio de una persona jurídica a la que podría encontrarse vinculado formal o materialmente.

Aquí también las victimas serían los competidores afectados por las decisiones de contratación de bienes o servicios que se adoptaron en clave de contraprestación por los beneficios indebidos prometidos, ofrecidos o concedidos a aquellos cuyo rol les posibilita realizar $\mathrm{u}$ omitir un acto que permita favorecer a otro(56).

Se castiga pues, la corrupción privada activa, toda vez que la sanción está dirigida al particular sin cualidad especial que promete, ofrece o concede (verbos rectores) un beneficio (dinero o cualquier otro medio corruptor) al sujeto con cualidades especiales al interior de la persona jurídica (socio, accionista, gerente, director, etc.) a cambio de

(54) Ver al respecto: Estudio Rodrigo Elías \& Medra Alerta Cumplimiento Normativo. Decreto Legislativo 1385 - Decreto Legislativo que sanciona la corrupción en el ámbito privado, 2018. Recuperado de internet: https://www.estudiorodrigo.com/alerta-cumplimientocorporativo-4/ (consultada el 01 de marzo de 2019).

(55) En igual sentido Estudio Rodrigo Elías \& Medra Alerta Cumplimiento Normativo. Decreto Legislativo 1385 - Decreto Legislativo que sanciona la corrupción en el ámbito privado, 2018. Recuperado de internet: https://www.estudiorodrigo.com/alerta-cumplimientocorporativo-4/ (consultada el 01 de marzo de 2019).

(56) En igual sentido Estudio Rodrigo Elías \& Medra Alerta Cumplimiento Normativo. Decreto Legislativo 1385 - Decreto Legislativo que sanciona la corrupción en el ámbito privado, 2018. Recuperado de internet: https://www.estudiorodrigo.com/alerta-cumplimientocorporativo-4/ (consultada el 01 de marzo de 2019). 
Análisis de la tipificación de la corrupción privada en el Perú: ¿Una estrategia global contra la corrupción también debe involucrar a los particulares? ¿Y a las empresas?

An Analysis of the Criminal Typification of Private Corruption in Peru: Should a global strategy against corruption involve the private sector? And what about companies?

que se favorezca a el mismo u otro (persona natural o jurídica) en la adquisición o comercialización de bienes o mercancías, en la contratación de servicios comerciales o en las relaciones comerciales. La corrupción privada activa tampoco admite modalidad subsecuente.

Al igual que en el caso anterior, la tramitación de esta modalidad también es de acción pública, es decir, que la persecución de dicho delito se encontrará a cargo del Ministerio Público, el cual podrá intervenir de oficio o a partir de la denuncia interpuesta por cualquier persona.

\subsection{El delito de corrupción al interior de entes privados (Artículo 241- B)}

Junto al delito de corrupción en el ámbito privado, el Decreto legislativo 1385 incorporó el artículo 241-B, que tipificó el delito de "corrupción al interior de entes privados", que sanciona los actos de deslealtad de los socios, accionistas, gerentes, directores, administradores, representantes legales, apoderados, empleados o asesores de las personas jurídicas que le causen, a cambio de algún beneficio propio o para un tercero, un perjuicio.

El contexto típico de este delito, entonces, se circunscribe a actos desarrollados en la gestión de la empresa, propios de su organización, y a los deberes que deben observar las personas que actúan en su representación. Se trata pues, de actos desarrollados en el fuero interno de la persona jurídica, y no de actos de interacción comercial con otras personas jurídicas.

La competencia leal no sería, entonces, el bien jurídico protegido en este ilícito penal, sino los deberes de lealtad que deben respetar quienes actúen en representación de la persona jurídica o aquellos que tomen decisiones que pueden

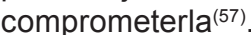

Dicho bien jurídico que también es protegido por el delito de fraude en la administración de personas (artículo 198 del
Código Penal), cuyo ámbito de protección según García Cavero- excede el patrimonio social de las personas jurídicas y busca más bien "la vigencia de la expectativa normativa de conducta (...) de que los directivos o administradores de una persona jurídica no incumplirán sus deberes de lealtad patrimonial frente a esta o no abusarán de sus facultades de administración en perjuicio de terceros vinculados" (2015, 399-400).

Ello debido a que existe un interés general en evitar que al interior de las personas jurídicas se desarrollen conductas que afecten intereses patrimoniales de sus miembros o socios, acreedores o terceros ${ }^{(58)}$, dada la importancia que tienen en el desarrollo de nuestra economía; lo cual es resaltado por Reategui, al indicar lo siguiente:

(...) los grandes capitales o inversiones nacionales o extranjeras, los grandes negocios o transacciones de bienes y servicios se mueven en función a pequeñas y grandes agrupamientos de personas físicas, en post de alcanzar objetivos comunes., por ende el Estado, a través de los controles jurídicos extrapenales y también penales necesita dar una debida protección para su real funcionamiento de las personas jurídicas en nuestra sociedad ${ }^{(59)}$.

Esta coincidencia en el ámbito de protección, entre el delito de corrupción al interior de las personas jurídicas y el delito de fraude en la administración de las personas jurídicas, quizá, podría ocasionar que en

(57) Véase: Daniel Quispe y David Torres. D.L. 1385: Estos son los alcances del decreto que sanciona la corrupción en lo privado (Idehpucp, 2018). Recuperado de internet: http://idehpucp.pucp.edu.pe/notas-informativas/d-l-1385-estos-son-los-alcances-deldecreto-que-sanciona-la-corrupcion-en-lo-privado/ (consultada el 01 de marzo de 2019); Carlos Caro Coriaen Entrevista en Canal $\mathrm{N}$ del 04 de setiembre de 2018. Recuperada de internet: https://www.ccfirma.com/sin-categorizar/carlos-caro-en-canal-n-sobre-eld-leg-n1385-corrupcion-empresarial/ (consultada el 01 de marzo de 2019); Estudio Rodrigo Elías \& Medra Alerta Cumplimiento Normativo. Decreto Legislativo 1385 - Decreto Legislativo que sanciona la corrupción en el ámbito privado, 2018. Recuperado de internet: https://www.estudiorodrigo.com/alerta-cumplimiento-corporativo-4/ (consultada el 01 de marzo de 2019).

(58) James Reátegui Sánchez. "Capítulo III. El delito de fraude en la administración de las personas jurídicas", en Derecho penal económico. Parte especial, (coaut) Caro Coria, Reyna Alfaro y Reátegui Sánchez, t II (Lima: Jurista Editores, 2016$), 99$.

(59) James Reátigui SA. "Capítulo III. El delito de fraude en la administración de las personas jurídicas", en Derecho penal económico. Parte especial, (coaut) Caro Coria, Reyna Alfaro y Reategui Sánchez, t II (Lima: Jurista Editores, 2016), 99-100. GALVEZ VILLEGAS, aun cuando piensa que el delito de fraude en la administración de las personas jurídicas protege solo el patrimonio social de la empresa, reconoce que la jurisprudencia comparada, como la italiana, reconoce dicho ilícito es uno "pluriofensivo, por cuanto no solo protegen intereses patrimoniales de los socios o terceros, de cualquier modo, afectados, sino que también el interés general en el regular funcionamiento de la sociedad comercial en el ámbito de la economía del país, pues estas conductas delictivas constituyen también hechos lesivos de la economía pública". Aladino Gálvez Villegas y Walther Delgado Tovar. Derecho penal. Parte Especial, t II, primera edición (Lima: Jurista editores, 2011), 1060. 
ciertos casos se generen problemas concursales. Por ello, si de lo que se trataba era de ampliar la protección de los deberes de lealtad que se deben observar al interior de las personas jurídicas, posiblemente hubiese sido más acertado que se adicione dicha conducta al delito de fraude en la administración de las personas jurídicas.

El Decreto Legislativo 1385 nos ha dejado un escenario confuso con la tipificación de este ilícito penal, que no estarían relacionado -en estricto- a las conductas referidas a la corrupción en el ámbito privado, pues no protege la competencia deslelal, sino los deberes de lealtad de quienes anteponen su propio beneficio al de la persona jurídica que representan.

Sin perjuicio de esto, es importante indicar que el artículo 241-A también presenta dos modalidades que dan lugar al hecho típico: modalidad pasiva y modalidad activa. Se sanciona así, tanto a aquella persona vinculada a la estructura de la persona jurídica (socio, accionista, gerente, director, etc.) que recibe un soborno (ventaja indebida) como también sanciona a aquella que lo entrega o promete. $Y$, a diferencia del delito de corrupción en el ámbito privado (artículo 241-A), este ilícito penal no se limita al contexto de adquisición o comercialización de bienes o mercancías o de contratación de servicios comerciales o relaciones comerciales.

Además, cabe indicar que, en cualquiera de las dos modalidades, el consentimiento de la persona jurídica no eximirá al agente de la responsabilidad penal por el hecho realizado. Sin embargo, sí tendrá efectos de cara a su persecución, toda vez que, a diferencia del delito de corrupción en el ámbito privado (artículo 241-A del Código Penal), solo la persona jurídica afectada se encontrará habilitada para denunciar el hecho, en tanto que se trata de un delito de acción privada.

Finalmente, debemos señalar que no nos queda clara la razón por la cual se realiza esta diferenciación, sobre todo si la tutela que se brinda a través de la de actos de corrupción al interior de entes privados trasciende al interés de las personas jurídicas afectadas, tan es así que el delito de fraude en la administración de las personas jurídicas, que protegería el mismo bien jurídico como lo hemos indicado, es de acción pública.

4.2.1. Primera modalidad: La corrupción al interior de entes privados pasiva (Primer Párrafo del Artículo 241- B):

El socio, accionista, gerente, director, administrador, representante legal, apoderado, empleado o asesor de una persona jurídica de derecho privado, organización no gubernamental, asociación, fundación, comité, incluidos los entes no inscritos o sociedades irregulares, que directa o indirectamente acepta, recibe o solicita donativo, promesa o cualquier otra ventaja o beneficio indebido de cualquier naturaleza para sí o para un tercero para realizar u omitir un acto en perjuicio de la persona jurídica, será reprimido con pena privativa de libertad no mayor de cuatro años e inhabilitación conforme al inciso 4 del artículo 36 del Código Penal y con ciento ochenta a trescientos sesenta y cinco días-multa.

De acuerdo a lo indicado en el artículo 241-B, el sujeto activo de este ilícito penal debe de tener una cualidad específica, como es la de ser socio, accionista, gerente, director, administrador, representante legal, apoderado, empleado o asesor de una persona jurídica de derecho privado, organización no gubernamental, asociación, fundación, comité, incluso los entes no inscritos o sociedades irregulares. La conducta prohibida consiste en que el sujeto que posee aquel particular rol al interior de la persona jurídica acepte, reciba o solicite un donativo, promesa o cualquier otra ventaja o beneficio indebido de cualquier naturaleza a cambio de realizar $u$ omitir un acto que genere un perjuicio en la persona jurídica. El sujeto activo puede realizar dicha conducta de manera directa o indirecta y en beneficio propio o de un tercero.

En este caso, para dar por consumado el delito será determinante que se haya generado un perjuicio a la persona jurídica vinculada con el sujeto activo del ilícito. El cual no necesariamente debe ser de carácter económico, sino que podría incluir cualquier acto que, por ejemplo, pueda provocar el cierre o extinción de la persona jurídica. La conducta debe ser realizada de manera dolosa.

4.2.2. Segunda modalidad: La corrupción al interior de entes privados activa (Segundo Párrafo del Artículo 241- B):

Será reprimido con las mismas penas previstas en el párrafo anterior quien, directa o indirectamente, promete, ofrece o concede a accionistas, gerentes, directores, administradores, representantes legales, apoderados, empleados o asesores de una persona jurídica de derecho privado, organización no gubernamental, asociación, fundación, comité, incluidos los entes no inscritos o sociedades irregulares, una ventaja o beneficio indebido de cualquier naturaleza, para ellos o para un tercero, como contraprestación para realizar $u$ omitir un acto en perjuicio de la persona jurídica. 
Análisis de la tipificación de la corrupción privada en el Perú: ¿Una estrategia global contra la corrupción también debe involucrar a los particulares? ¿Y a las empresas?

An Analysis of the Criminal Typification of Private Corruption in Peru: Should a global strategy against corruption involve the private sector? And what about companies?

En el segundo párrafo del artículo 241-B se criminaliza el acto del particular que directa, o indirectamente, promete, ofrece o concede una ventaja o beneficio indebido de cualquier naturaleza (medios corruptores) a los accionistas, gerentes, directores, administradores, representantes legales, apoderados, empleados o asesores de una persona jurídica de derecho privado, organización no gubernamental, asociación, fundación, comité, incluso los entes no inscritos o sociedades irregulares. Los medios corruptores (dinero o cualquier otro) serán prometidos, ofrecidos o concedidos con la finalidad de lograr que un miembro de la persona jurídica realice u omita un acto que le genere un perjuicio a esta última. La conducta debe ser dolosa. Se trata de un delito de acción privada.

\section{Los programas de cumplimiento normativo dentro del marco de la Ley 30424 - Responsabilidad Administrativa (penal) de las personas jurídicas}

Un último punto que se deriva de la importancia que tiene el rol de las personas jurídicas en la prevención de la corrupción, y en específico de la corrupción privada, es resaltar que esta tarea no puede llevarse a cabo de forma eficiente si no se promueve en las personas jurídicas la implementación de los programas de cumplimiento, conforme lo determina la Ley 30424 y los documentos más importantes que se han elaborado sobre la lucha contra la corrupción.

En efecto, desde enero del 2018, a partir de la entrada en vigencia de la Ley que regula la responsabilidad administrativa de la persona jurídica (Ley 30424), al margen de la denominación empleada( ${ }^{(60)}$, en nuestro país es posible responsabilizar a una persona jurídica por su involucramiento en la realización de algunos delitos, debido a la defectuosa configuración de su ámbito de organización y a la inexistencia de una cultura de incumplimiento de la legalidad que permitió que se cometa dicho ilícito, ello de forma independiente a la condena de una persona natural.

Son precisamente dichas particularidades, unidas a otras que han sido explicadas en una anterior contribución académica ${ }^{(61)}$, las que nos permiten sostener que las sanciones establecidas en la Ley 30424 responden al propio injusto de la persona jurídica, que será valorado por un juez penal, a solicitud de la fiscalía, en el marco y con las garantías de un proceso penal, mediante la aplicación de los instrumentos que la dogmática penal ofrece para evaluar si la persona jurídica es o no un buen ciudadano corporativo.

El modelo adoptado por la Ley 30424 sería uno de carácter mixto(62), pues se aprecia de las distintas disposiciones de dicha norma que se parte del modelo de atribución de responsabilidad penal por el hecho de otro para luego orientarse hacia la responsabilidad por el hecho propio de la persona jurídica (Palomino y Madrid, 2019).

Por esto, si se acreditase la responsabilidad de la persona jurídica, según el artículo 6 de la Ley 30424, se le podrá aplicar -de manera proporcional- las siguientes sanciones, según corresponda: i) multa ${ }^{(63)}$, ii) inhabilitación en cualquiera de sus modalidades (como suspensión de sus actividades sociales o inhabilitación para contratar con el Estado de carácter definitiva), iii) cancelación de licencias, concesiones, derechos y otras autorizaciones administrativas o municipales, iv) clausura de sus locales o establecimientos, con carácter temporal o definitivo, y/o ii) disolución ${ }^{(64)}$.

Ahora bien, en la medida de que las personas jurídicas muchas veces ofrecen un escenario propicio para la realización de delitos relacionados a la corrupción, como lo ha advertido todos los instrumentos internacionales y nacionales que hemos referido en el punto 2 y 3 del presente artículo, las sanciones previstas en la Ley 30424 están reguladas -en su mayoría- para ilícitos que

(60) Sobre el carácter penal de la responsabilidad autónoma de las personas jurídicas previsto en la Ley 30424 puede consultarse: Walter Palomino Ramírez y Cecilia Madrid Valerio. "Responsabilidad "administrativa" de las personas jurídicas e importancia de los programas de cumplimiento, a apropósito del Decreto Legislativo n. ${ }^{\circ}$ 1352”. Actualidad Penal 38, marzo 2017.

(61) Sobre el carácter penal de la responsabilidad autónoma de las personas jurídicas previsto en la Ley 30424 puede consultarse: Walter Palomino Ramírez y Cecilia Madrid Valerio. "Responsabilidad "administrativa" de las personas jurídicas e importancia de los programas de cumplimiento, a apropósito del Decreto Legislativo n. 1352”. Actualidad Penal 38, marzo 2017.

(62) Adán Nieto Martín. "La responsabilidad penal de las personas jurídicas en Perú: consideraciones desde una perspectiva comparada". Boletín Académico n. ${ }^{\circ}$ 48, Lima, 2018. Recuperado de internet: http://www.oreguardia.com.pe/media/uploads/derecho-penal/ Ad\%C3\%A1n-Nieto,-LA-RESPONSABILIDAD-PENAL-DE-LAS-PERSONAS-JUR\%C3\%8DDICAS-EN-PER\%C3\%9A.pdf (consulta el 29 de marzo de 2019).

(63) No menor al doble ni mayor al séxtuplo del beneficio obtenido o que se espera obtener la persona jurídica con la comisión del delito.

(64) Que solo es aplicable a las personas jurídicas que hayan sido constituidas para favorecer, facilitar o encubrir la comisión de delitos. 
reprimen la corrupción pública. En virtud a ello, es razonable pensar que la corrupción privada engrosará el catálogo de delitos que conducen a la responsabilidad administrativa (penal) de la persona jurídica, toda vez que, en el marco de una estrategia integral de lucha contra la corrupción, es lógico que se sancionen a todas aquellas personas jurídicas que no se comportan como buenos ciudadanos corporativos al beneficiarse de los actos corruptos de sus integrantes.

Además, en vista que el objeto de la criminalización de los actos de corrupción entre privados, realizado vía el Decreto Legislativo 1385, es "(...) sancionar penalmente los actos de corrupción cometidos entre privados que afectan el normal desarrollo de las relaciones comerciales y la competencia leal entre empresas" (énfasis añadido), puede deducirse que, una idea tacita en dicha norma es que una defectuosa organización del riesgo que conllevan las actividades que realizan las de personas jurídicas podría provocar serías ofensas a determinadas condiciones necesarias para el ejercicio de los derechos colectivos en sociedad (Meini 2014, 30).

Asimismo, vale la pena recordar que la Ley 30424 ha sido modificada hasta en dos oportunidades con el propósito, entre otras cosas, de ampliar el catálogo de ilícitos que permiten responsabilizar a las personas jurídicas ${ }^{(65)}$, por lo que no es improbable que el legislador amplíe nuevamente dicho catálogo de ilícitos penales para que también se sancionen a las personas jurídicas que se benefician de los actos corruptos cometidos por sus integrantes en el marco de la contratación de servicios comerciales o en las relaciones comerciales realizadas entre privados.

También es oportuno indicar que, en Informe Final de la Comisión Presidencial de Integridad del año $2016^{(66)}$, se propuso la promoción de la integridad en el sector privado como una de las principales medidas para prevenir y sancionar la corrupción en nuestro país ${ }^{(67)}$. Para ello, se puso hincapié en la necesidad de una implementación progresiva de programas de prevención contra prácticas de corrupción en las personas jurídicas, los cuales se considerarían como eximentes de responsabilidad para la persona jurídica, lo que -como tuvimos oportunidad de comentar ${ }^{(68)}$ - da cuenta de la importancia del establecimiento de dichos mecanismos diseñados específicamente para mitigar el riesgo de incurrir en infracciones legales ${ }^{(69)}$.
Por ello mismo, debe tomarse en cuenta que, a nivel comparado, desde hace mucho tiempo se han desarrollado diversas guías para orientar a las personas jurídicas en dicha labor, dada la importancia para la prevención global de la corrupción. De estas, resaltamos dos instrumentos fundamentales, por un lado, el Decálogo de Principios de Transparencia y Prevención de la Corrupción para Empresas que, en el año 2012, lanzó Transparencia Internacional, donde se estableció que para combatir los casos de corrupción en el sector privado las empresas se deben regir por los siguientes principios: cumplimiento de los principios de buen gobierno corporativo, implementación en la empresa de un código ético, implementación de programas de cumplimiento normativo. creación de canales para denunciar el incumplimiento de normas, información pública de las retribuciones de los directivos y de los administradores, información de contrataciones y actividades subvencionadas, información pública de las políticas de responsabilidad social corporativa, evitación de prácticas de favorecimiento y corrupción en el sector privado, evitación de prácticas de corrupción de funcionarios extranjeros en las transacciones internacionales, cumplimiento de las obligaciones fiscales.

$Y$ por otro, la norma internacional ISO 370001 , que ha desarrollado con mayor detalle las medidas de prevención que debe desarrollar una persona jurídica para combatir la corrupción, cuya norma técnica peruana fue aprobada en marzo del 2017 por la Dirección de Normalización del Instituto Nacional de la Calidad - INACAL.

La ISO 37001 maneja un concepto amplio de corrupción, pues define el soborno como la "oferta, promesa, entrega, aceptación

(65) Así, mediante el Decreto Legislativo 1352 se incluyeron los ilícitos penales de cohecho activo genérico, cohecho activo específico, lavado de activos y financiamiento del terrorismo; luego, a través de la Ley 30835, se incorporó la colusión ilegal y el tráfico de influencias dentro de los ilícitos que pueden conducir a la responsabilidad administrativa (penal) de la persona jurídica.

(66) Emitida el 04 de diciembre de 2016.

(67) Para ello, se partió de la idea de que, si bien es evidente la importancia de las personas jurídicas en las relaciones económicas o comerciales, se reconoce también el alto riesgo de corrupción que podría afectar a las empresas; razón por la cual, se consideró necesaria una actuación conjunta entre el Estado y el sector privado a fin de promover la integridad y la lucha contra la corrupción. Ver al respecto: Informe Final de la Comisión Presidencial de Integridad, de fecha 4 de diciembre de 2016, pp. 20-21.

(68) Walter Palomino Ramírez y Cecilia Madrid Valerio. "Responsabilidad "administrativa" de las personas jurídicas e importancia de los programas de cumplimiento, a apropósito del Decreto Legislativo n. ${ }^{\circ}$ 1352”. Actualidad Penal 38, marzo 2017.

(69) Asimismo, en el mencionado documento se planteó la ampliación del régimen de responsabilidad de las personas jurídicas. Al respecto: Walter Palomino Ramírez y Cecilia Madrid Valerio. "Responsabilidad "administrativa" de las personas jurídicas e importancia de los programas de cumplimiento, a apropósito del Decreto Legislativo n. 1 1352”. Actualidad Penal 38, marzo 2017. 
Análisis de la tipificación de la corrupción privada en el Perú: ¿Una estrategia global contra la corrupción también debe involucrar a los particulares? ¿Y a las empresas?

An Analysis of the Criminal Typification of Private Corruption in Peru: Should a global strategy against corruption involve the private sector? And what about companies?

o solicitud de una ventaja indebida de cualquier valor (de naturaleza financiera o no financiera), [que] directamente o indirectamente [se da como] (...) incentivo o recompensa para que una persona actúe o deje de actuar en relación con el desempeño de las obligaciones de esa persona"(70). En función a ello, desarrolla un sistema de gestión antisoborno para que las organizaciones prevengan, de manera razonable y proporcional(71), actos de soborno que pueden surgir tanto en su interacción con entes públicos como con privados.

Esta norma internacional propone que, en esta tarea de prevención, la organización implemente controles financieros ${ }^{(72)}$ y no financieros ${ }^{(73)}$ que gestionen el riesgo soborno en sus diversas áreas, como en compras, operaciones, ventas, comercial, recursos humanos, y actividades legales y regulatorias ${ }^{(74)}$; además de la implementación de procedimientos destinados a prevenir la oferta, el suministro o la aceptación de regalos, atenciones, donaciones y beneficios similares que razonablemente podrían ser percibidos como soborno(75).

De todas las medidas que la ISO 37001 prevé, aquellas que principalmente pueden ser implementadas para prevenir el riesgo de soborno entre privados, son las siguientes:

\begin{tabular}{|c|c|c|}
\hline Controles financieros ${ }^{(76)}$ & Controles no financieros ${ }^{(77)}$ & $\begin{array}{l}\text { Política de regalos, atenciones, donaciones y } \\
\text { beneficios similares }{ }^{(78)}\end{array}$ \\
\hline $\begin{array}{l}\text { - Implementar separación de funciones en } \\
\text { la aprobación de los pagos. } \\
\text { - Intervención de funcionarios de diversos } \\
\text { niveles en la aprobación de los pagos, en } \\
\text { función a la envergadura de los mismos. } \\
\text { - Incorporar topes máximos para el uso de } \\
\text { dinero en efectivo } \\
\text { - Implementar métodos de control efectivo } \\
\text { de caja chica. } \\
\text { - Documentar de forma adecuada los pagos } \\
\text { para que las decisiones sobre su aproba- } \\
\text { ción puedan ser más eficientes. } \\
\text { - Implementar revisiones periódicas de } \\
\text { la gestión de operaciones financieras } \\
\text { relevantes. } \\
\text { - Implementar auditorias financieras perió- } \\
\text { dicas independientes. } \\
\text { - Cambiar de forma regular a los encarga- } \\
\text { dos de realizar tales auditorías. }\end{array}$ & $\begin{array}{l}\text { - Implementar mecanismos de debida diligencia para los } \\
\text { procesos de contratación de la organización. } \\
\text { - Implementar un proceso de precalificación de los provee- } \\
\text { dores, subcontratistas y consultores que presten servicios } \\
\text { a la organización. } \\
\text { - Implementar mayores controles a los servicios realiza- } \\
\text { dos por socios de negocios, para evaluar su legitimidad, } \\
\text { cumplimiento y costo. } \\
\text { - Controlar la proporcionalidad de los honorarios de éxito en } \\
\text { los servicios que decida otorgar la organización. } \\
\text { - Implementar mecanismos competitivos, transparentes y } \\
\text { justos de contratación. } \\
\text { - Requerir de al menos dos personas que evalúen las ofertas } \\
\text { y aprueben las adquisiciones. } \\
\text { - Implementar una separación de funciones, entre quienes } \\
\text { aprueban del contrato, quienes solicitan el servicio y quienes } \\
\text { aprueban el contrato realizado. } \\
\text { - Implementar controles contractuales para la modificación } \\
\text { de los contratos, en el que intervengan por lo menos dos } \\
\text { personas de la organización. } \\
\text { - Establecer la intervención de un nivel superior de supervi- } \\
\text { sión en la gestión de operaciones con alto riesgo de sobor } \\
\text { - Resguardar la información de ofertas y precios de los } \\
\text { procesos de adquisición. }\end{array}$ & $\begin{array}{l}\text { - Evitar, tanto como sea posible, cualquier regalo, } \\
\text { atenciones, donaciones u otros beneficios similares } \\
\text { que podrían razonablemente ser percibidos por una } \\
\text { tercera parte como un sobor } \\
\text { - Regular las siguientes prestaciones: regalos, } \\
\text { entretenimiento y atenciones; donaciones políticas } \\
\text { o de caridad; viaje de representantes de clientes } \\
\text { o funcionarios públicos; gastos de promoción; } \\
\text { auspicio; beneficios para la comunidad; formación; } \\
\text { membresías a clubes; favores personales; informa- } \\
\text { ción confidencial y privilegiada. } \\
\text { - Limitar los regalos y atenciones en función a } \\
\text { diversos factores como el valor máximo, frecuen- } \\
\text { cia, oportunidad, razonabilidad, entorno legal y } \\
\text { regulatorio, etc. } \\
\text { - Estos controles deben regular tanto las atenciones } \\
\text { que da la empresa, como las que recibe. } \\
\text { - Implementar controles de aprobación de regalos en } \\
\text { función al valor, oportunidad o frecuencia. } \\
\text { - Implementar mecanismos de transparencia en la } \\
\text { recepción de regalos (registro) que se supervise. } \\
\text { - Implementar mecanismos de transparencia de } \\
\text { las donaciones de la organización, los mismos que } \\
\text { deben cumplir las exigencias de la Ley y reglamen- } \\
\text { tos aplicables. }\end{array}$ \\
\hline
\end{tabular}

(70) Punto 3.1 de la Norma Técnica Peruana ISO 37001.

(71) Punto 4.4 de la Norma Técnica Peruana ISO 37001.

(72) Son "sistemas de gestión y procesos implementados por la organización para gestionar sus operaciones financieras correctamente y para registrar estas operaciones con precisión, por completo y de manera oportuna". Anexo A.11 de la Norma Técnica Peruana ISO 37001.

(73) Esto es, "sistemas de gestión y procesos implementados por la organización para ayudar a asegurar que la adquisición, aspectos operacionales, comerciales y otros aspectos no financieros de sus actividades, se están gestionando correctamente". Anexo A.12 de la Norma Técnica Peruana ISO 37001.

(74) Punto 8.3 y 8.4 de la Norma Técnica Peruana ISO 37001.

(75) Punto 8.7 de la Norma Técnica Peruana ISO 37001.

(76) Anexo A.11 de la Norma Técnica Peruana ISO 37001.

(77) Anexo A.12 de la Norma Técnica Peruana ISO 37001.

(78) Anexo A.15 de la Norma Técnica Peruana ISO 37001. 
Como se puede advertir, el abanico de las medidas de prevención que la ISO 37001 propone para evitar el soborno privado es variado; sin embargo, esta norma internacional pone énfasis que todas estas medidas deben aplicarse de forma razonable, teniendo en cuenta las actividades de la organización, su estructura y su complejidad, para lo cual será fundamental que se realice antes un análisis del riesgo de soborno en todos los procesos de la empresa, solo de esta manera será posible encontrar el punto medio entre la prevención y la eficiencia en el desarrollo de las actividades de la organización.

\section{Conclusiones}

- Para combatir la corrupción es necesario que se procure una estrategia integral de persecución y sanción de todas las formas de corrupción, que acepte como necesaria la intervención del Derecho penal en contextos donde todos los intervinientes son particulares que realizan conductas que comunican un serio riesgo para importantes intereses públicos.

- La estructura del delito de corrupción entre privados (artículo 241-A) da cuenta de dos modalidades que dan lugar al hecho típico: corrupción pasiva y corrupción activa. En ambas lo que se afecta son las reglas de la leal competencia en el mercado que tienen como propósito que los bienes y servicios se ofrezcan en condiciones de competitividad abierta y libre.

- En el delito de corrupción al interior de entes privados (artículo 241- B) no serán las reglas de la leal competencia en el mercado el bien jurídico protegido, sino los deberes de lealtad que deben respetar quienes actúen en representación de la persona jurídica o aquellos que tomen decisiones que pueden comprometerla.

- En la realización de la conducta típica los delitos de corrupción en el ámbito privado (artículo 241-A) y corrupción al interior de entes privados (artículo 241- B), al menos, una persona jurídica se encontrará involucrada, sea como agraviada (artículo 241-B) o, incluso, en algunos supuestos, como una que se beneficie de los actos delictivos de sus integrantes (artículo 241-A).

- Es recomendable que las personas jurídicas sean especialmente cuidadosas en sus relaciones comerciales, pues, aunque muchas veces los obsequios constituyen un acto de cortesía, a partir de la incorporación de los delitos de corrupción privada tal conducta podría ser delictiva, por lo que las empresas deberán crear políticas de regalos que mitiguen el riesgo de incurrir en un acto de soborno conforme se encuentra descrito en el Decreto Legislativo 1385.

\section{Referencias Bibliográficas}

Abanto Vásquez, Manuel. 2001. Los delitos contra la Administración Pública en el Código Penal perua Lima: Palestra Editores.

Bregaglio Lazarte, Renata. 2015. "La lucha contra la corrupción en el Ordenamiento Internacional". En Aproximación multidisciplinaria para el procesamiento de casos de corrupción en el Perú. Lima: Idehpucp - USAID. Recuperado de internet: http://idehpucp.pucp.edu.pe/wp-content/ uploads/2015/10/Aproximaci\%C3\%B3nMultidisciplinaria-para-el-Procesamientode-Casos-de-Corrupci\%C3\%B3n-en-elPer\%C3\%BA.pdf (consultado el 01 de marzo de 2019).

Bolea Bardon, Carolina. 2013. "El delito de corrupción privada. Bien jurídico, estructura típica e intervinientes". En Indret: Revista para el Análisis del Derecho, número 2, (marzo). Recuperado de internet: http://diposit.ub.edu/ dspace/bitstream/2445/53524/1/624079.pdf.

Convención de las Naciones Unidas contra la Corrupción. 2004. Naciones Unidas. Oficina contra la Droga y el Delito. Recuperado de internet: https://www.unodc.org/pdf/corruption/ publications_unodc_convention-s.pdf.

Encinar Del Pozo, Miguel. 2017. El delito de corrupción entre particulares del artículo 286bis del Código Penal. Memoria para optar el grado académico de Doctor (dirigida por Jacobo Lope Barja de Quiroga). Universidad Complutense de Madrid.

Estudio Rodrigo Elías \& Medra 2018. Alerta Cumplimiento Normativo. Decreto Legislativo 1385 - Decreto Legislativo que sanciona la corrupción en el ámbito privado. Recuperado de internet: https://www.estudiorodrigo. com/alerta-cumplimiento-corporativo-4/ (consultada el 01 de marzo de 2019).

Faraldo Cabana, Patricia. 2000. Hacia un delito de corrupción en el sector privado. Conferencia elaborada para el "II Congreso Hispano- Italiano de Derecho penal económico, celebrado los días 21 al 23 de setiembre de 2000" en Pavia. Recuperado de internet: http://blog.uclm.es/ cienciaspenales/files/2016/11/3_hacia-undelito-de-corrupcion.pdf. 
Análisis de la tipificación de la corrupción privada en el Perú: ¿Una estrategia global contra la corrupción también debe involucrar a los particulares? ¿Y a las empresas?

An Analysis of the Criminal Typification of Private Corruption in Peru: Should a global strategy against corruption involve the private sector? And what about companies?

Galvez Villegas, Aladino y DELGADO TÓVAR, Walther. 2011. Derecho penal. Parte Especial. Tomo II, primera edición. Lima: Jurista editores.

García Cavero, Percy. 2012. Derecho penal. Parte general, segunda edición. Lima: Jurista Editores.

2015. Derecho penal económico. Parte especial. Vol. I, $2^{\text {da }}$ edición. Lima: Instituto Pacífico.

Gili Pascual, Antoni. 2007. Bases para la delimitación del ámbito típico en el delito de corrupción privada. Contribución al análisis del artículo 286 bis del Código Penal según el Proyecto de reforma de 2007. Revista Electrónica de Ciencia Penal y Criminología 09. Recuperado de internet: http://criminet.ugr. es/recpc/09/recpc09-13.pdf.

Gómez-Jara Díez, Carlos. 2012. Capítulo1. El sistema de responsabilidad penal de las personas jurídicas en el nuevo Código Penal español. En El nuevo Código Penal, coord.. Nuria Pastor Muñoz y Jesús María Silva Sanchez (dir.), 43-102. España: Madrid.

2008. Corrupción en el sector privado: ¿competencia desleal y/o administración desleal? Revista cuatrimestral de las Facultades de Derecho y Ciencias Económicas y Empresariales 74, mayo-agosto. Recuperado de internet: https://revistas. upcomillas.es/index.php/revistaicade/article/viewFile/355/281.

Hurtado Pozo, José. Corrupción y Derecho penal, Recuperado de internet: http://perso.unifr.ch/derechopenal/assets/files/ articulos/a_20140608_02.pdf.

Informe Final de la Comisión Presidencial de Integridad. 2016. Perú: Comisión Presidencial de Integridad formada en el Gobierno del Presidente Pedro Pablo Kucynsky. Recuperado de internet: https://plataformaanticorrupcion.pe/wp-content/ uploads/2017/07//nforme-Final-Comision-Presidencial-deIntegridad.pdf.

Jiménez Valderrama, Fernando y García Rodríguez, Lourdes. 2015. "El interés jurídico protegido en el delito de corrupción privada en Colombia. Análisis de contexto y conexiones con el derecho de la competencia desleal". IUS Revista del Instituto de Ciencias Jurídicas de Puebla 35, Año IX. Recuperado de internet: http://www.scielo.org.mx/pdf/rius/v9n35/1870-2147rius-9-35-00159.pdf.

Líneas Directrices de la OCDE para empresas multinacionales. 2011. OCDE: OECD Publishingp. Recuperado de internet: https://www.oecd.org/daf/inv/mne/MNEguidelinesESPANOL. pdf.

Lopera Mesa, Gloria. 2010. "Principio de proporcionalidad y control constitucional de las leyes penales". En: El principio de proporcionalidad en el Derecho contemporáneo. Cuadernos de análisis y crítica a la jurisprudencia constitucional 8, (cood.) CARBONELL/ GRÁNDEZ CASTRO. Lima: Palestra.
Meini, Iván. 2007. Delitos contra la Administración Pública. Con arreglo al Código Penal de la República de Panamá (Ley 14 de 18 de mayo de 2007) y a las Convenciones Internacionales contra la corrupción firmadas y ratificadas por panamá. Serie de publicaciones. Lecciones aprendidas y buenas prácticas en el Ministerio Público de Panamá. Guatemala: USAID.

2014. Lecciones de Derecho Penal Parte General. Teoría jurídica del delito. Lima: Fondo Editorial PUCP.

Mir Puig, Santiago. 2009. "El principio de proporcionalidad como fundamento constitucional de límites materiales del Derecho penal". En: Constitución, derechos fundamentales y sistema penal, (Dir.) CARBONEL, GONZALES y ORTS. Valencia: Tirant Le Blanch. Recuperado de internet: http://www.fder.edu.uy/contenido/penal/ pdf/2010/extranjeros/mir-puig-principio-deproporcionalidad.pdf.

Montoya Vivanco, Yván. 2012. ¿Por qué no penalizar la corrupción privada? en: Proyecto Anticorrupción, Boletín 10, marzo. Recuperado de internet: Recuperado de internet: http:// cdn01.pucp.education/idehpucp/wp-content/ uploads/2017/06/30213651/2012_boletin10. pdf.

coord. 2015. Manual sobre delitos contra la administración pública. Lima: Idehpucp - Open Society Foundations.

Nieto Martín, Adán. 2018 "La responsabilidad penal de las personas jurídicas en Perú: consideraciones desde una perspectiva comparada". Boletín Académico 48. Recuperado de internet: http://www.oreguardia.com.pe/ media/uploads/derecho-penal/Ad\%C3\%A1nNieto,-LA-RESPONSABILIDAD-PENAL-DELAS-PERSONAS-JUR\%C3\%8DDICAS-ENPER\%C3\%9A.pdf.

Norma Técnica peruana ISO 37001. 2017. Perú: Dirección de Normalización del Instituto Nacional de la Calidad - INACAL.

Novoa Curich, Yvana. 2016. "La corrupción como mecanismo de discriminación". Derecho y Sociedad 47. Recuperado de internet: http://revistas.pucp.edu.pe/index.php/ derechoysociedad/issue/view/1428. 
OCDE. 2017. Estudio de la OCDE sobre la Integridad en el Perú. Resultados y Recomendaciones. Recuperado de internet: https://www.oecd.org/gov/ethics/peruestudio-integridad-folleto.pdf.

Oficina de Naciones Unidas contra la Droga y el Delito en Viena. 2013. Programa Anticorrupción de ética y cumplimiento para las empresas: Guía práctica. Recuperado de internet: https://www.unodc.org/documents/ corruption/Publications/2013/13-85255_ Ebook.pdf.

Palomino Ramírez, Walter. 2017. La exclusión del injusto en el estado constitucional y democrático de derecho: el riesgo permitido vs la justificación excepcional de comportamientos prohibidos. Tesis para la obtención de grado de Magister con mención en Derecho penal por la Pontificia Universidad Católica del Perú (inédito).

Palomino Ramírez, Walter y Madrid Valerio, Cecilia. 2017. "Responsabilidad "administrativa" de las personas jurídicas e importancia de los programas de cumplimiento, a apropósito del Decreto Legislativo 1352". Actualidad Penal 38, marzo.

2019. La reacción sancionadora del estado sobre las personas jurídicas en el marco del sistema penal perua Inédito.

Plan Nacional de Integridad y lucha contra la Corrupción 2018-2021. 2018. Perú: Comisión de Alto Nivel Anticorrupción. Recuperado de internet: http://can.pcm.gob.pe/wpcontent/uploads/2018/04/Decreto-SupremoN\%C2\%B0-048-2018-que-aprueba-el-PlanNacional-de-Integridad-y-Lucha-contra-laCorrupci\%C3\%B3n-2018-2021.pdf.

Política Nacional de integridad y lucha contra la Corrupción. 2017. Perú: Comisión de Alto Nivel Anticorrupción. Recuperado de internet: http://can.pcm.gob.pe/normas-nacionales/ politica-nacional-de-integridad-y-luchacontra-la-corrupcion/.

Prado Saldarriaga, Víctor. 2017. Recientes desarrollos de las políticas internacionales contra la corrupción en el Perú. Conferencia presentada en "IV Conferencia Anticorrupción.
Instrumentos Internacionales en la lucha Anticorrupción", 17 de mayo de 2017, en Lima. Recuperado de internet: https://www.pj.gob. pe/wps/wcm/connect/4c335e004243aebdb74ff70655a61feb/ Recientes+desarrollos+de+las+pol\%C3\%ADticas+internacionales +contra+la+corrupci\%C3\%B3n+en+el+Per\%C3\%BA.pdf?MOD= AJPERES\&CACHEID=4c335e004243aebdb74ff70655a61feb.

2017. Delitos y penas. Una aproximación a la Parte Especial. Lima: Ideas Solución Editorial SAC.

Quispe, Daniel y Torres, David. 2018. D.L. 1385: Estos son los alcances del decreto que sanciona la corrupción en lo privado. Idehpucp. Recuperado de internet: http://idehpucp.pucp.edu. pe/notas-informativas/d-I-1385-estos-son-los-alcances-deldecreto-que-sanciona-la-corrupcion-en-lo-privado/.

Reaño Peschiera, José. 2015 "La utilidad de los programas de criminal compliance para las empresas que operan en Perú". Revista PUCP 68. Recuperado de internet: http://www.revistas. pucp.edu.pe/index.php/themis/article/view/15589.

Reátegui Sánchez, James. 2016. "Capítulo III. El delito de fraude en la administración de las personas jurídicas". En Derecho penal económico. Parte especial, (coaut) Caro Coria, Reyna Alfaro y Reategui Sánchez. tomo II. Lima: Jurista Editores.

San Martín Castro, César. 2012. "Debate en panel: la lucha anticorrupción desde el sistema de justicia peruano". En: La lucha anticorrupción como política de Estado. V seminario de reforma del Estado, eds. Henry Pease García y Giofani Peirano Torriani, 41-47. Lima: Fondo Editorial PUCP.

Salinas Siccha, Ramiro. 2016. Delitos contra la Administración Pública. 4ta edición. Lima: Grijley.

Sánchez Velarde, Pablo. 2017. 100 acciones propuestas por el Fiscal de la Nación. Recuperado de internet: https:// plataformaanticorrupcion.pe/wp-content/uploads/2017/07/100medidas-anticorrupcion-JA.pdf (consultada el 01 de marzo de 2019).

Sanchez-Ostiz, Pablo. 2012. Fundamentos de una Política criminal. Un retorno a los principios. Madrid: Marcial Pons.

Terradillos Basoco, Juan María, "Corrupción, globalización y derecho penal económico. Lección de apertura del año académico de la Facultad de Derecho de la Pontificia Universidad Católica del Perú", Derecho PUCP 74 (2015). Recuperado de internet: http://revistas.pucp.edu.pe/index.php/ derechopucp/article/view/13585 (consultada el 01 de marzo de 2019).

Ugaz Sánchez-Moreno, José y Ugaz Heudebert, Francisco. 2017. Delitos económicos, contra la administración pública y criminalidad organizada. Colección Lo esencial del Derecho 18, Lima: Fondo Editorial PUCP. 